\title{
Avaliação do potencial de resfriamento de um sistema teto-reservatório para condições subtropicais
}

\author{
Evaluation of the cooling potential of a roof-pond system \\ under subtropical conditions
}

\section{Eduardo Leite Krüger \\ Sérgio Costa Lange \\ Leandro Fernandes \\ Francine Rossi}

Eduardo Leite Krüger Universidade Tecnológica Federal do Paraná Curitiba - PR - Brasil

Sérgio Costa Lange Universidade Tecnológica Federal do Curitiba - PR - Brasil

Leandro Carlos Fernandes Universidade Federal do Paraná Curitiba - PR - Brasil

Francine Aidie Rossi Universidade Federal do Paraná Curitiba - PR - Brasil

Recebido em 04/09/15 Aceito em 07/01/16

\section{Resumo}

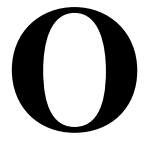

resfriamento evaporativo indireto (REI), caracterizado pela umidificação de coberturas e por produzir resfriamento sem aumentar a umidade relativa do interior da edificação, é uma estratégia de projeto bioclimático ainda relativamente pouco usada no horizonte brasileiro. O presente estudo tem por objetivo avaliar a aplicação de uma forma particular de REI (que alia o resfriamento evaporativo à inércia térmica propiciada por um reservatório d'água) para o condicionamento térmico de ambientes em situação de calor em Curitiba, cidade inserida na zona bioclimática 1. Foram confeccionados, monitorados e comparados inicialmente duas células-teste: um módulo de controle (MC) e um módulo experimental (ME), este dotado de uma cobertura estanque constituída de um reservatório d'água sujeita à evaporação. Uma segunda configuração do módulo experimental foi testada em um período de monitoramento subsequente, a qual possibilitou comparar-se o efeito do resfriamento com o reservatório vedado, ou seja, sem uso do REI, em uma situação de aumento da capacidade térmica da cobertura sem haver efeito evaporativo. Os resultados apontam para a vantagem do uso do REI para o resfriamento interno dos protótipos testados.

Palavras-chaves: Resfriamento passivo. Resfriamento evaporativo indireto. Massa térmica.

\section{Abstract}

Indirect evaporative cooling systems (IECS), characterized by the use of wetted roof or wall surfaces for cooling without increasing the indoor air moisture, consist of an interesting bioclimatic strategy is still little explored in Brazil. The paper aims to evaluate the use of a particular form of IECS (which combines evaporative cooling and thermal mass brought about by a water reservoir) for indoor thermal control in warm conditions in Curitiba, located within Bioclimatic Zone 1. Two scale models were initially built, monitored and compared to each other: a control module (CM) and an experimental module (EM), the latter provided with an evaporative pond. A subsequent configuration of the system which cancels out the evaporative function of the system, based on the increase of the roof's thermal capacitance by an enclosed water container, was tested in a second monitoring round. Thus the results showed a higher effectiveness of the IECS for the indoor cooling of the tested scale-models.

Keywords: Passive cooling. Indirect evaporative cooling. Thermal mass. 


\section{Introdução}

A preocupação em garantir maior eficiência energética às edificações tem como uma de suas razões, além do aumento geral das tarifas de energia observado no Brasil no presente ano, a geração de energia primária a qual vem paulatinamente ocorrendo a partir de fontes não renováveis. Devido a condições hidrológicas desfavoráveis, em 2012 e 2013 houve no Brasil uma redução da oferta de energia hidráulica. Em 2012 o decréscimo foi de 1,9\% (EMPRESA..., 2013), e em 2013 de 5,4\% (EMPRESA..., 2014). A menor oferta hídrica explica a retração da participação de renováveis (hidráulica + eólica + biomassa) na matriz elétrica, de 88,9\% em 2011 para 79,3\% em 2013, apesar do permanente incremento na potência instalada do parque hidrelétrico. Esse contexto leva a pesquisa na área do ambiente construído a buscar alternativas tecnológicas de baixo consumo energético. Em se tratando do condicionamento térmico de edificações, uma das estratégias de baixo consumo energético consiste no emprego de sistemas de resfriamento evaporativo. Tais sistemas podem ser agrupados em dois tipos: sistemas de resfriamento evaporativo direto e sistemas de resfriamento evaporativo indireto. $\mathrm{O}$ resfriamento evaporativo direto (RED) baseia-se em dispositivos para aspersão de água sob a forma de gotículas no interior dos ambientes.

$O$ ar cede calor sensível e as gotículas de água passam do estado líquido para o gasoso no ambiente interno e, como consequência, há decréscimo da temperatura e acréscimo da umidade relativa do ar [...] (VECCHIA; MASIERO, 2006, p. 544).

Essa alternativa tecnológica vem se popularizando rapidamente e avançam estudos sobre seu potencial (BATISTA; LAMBERTS, 2007; SILVA, 2004). O REI, caracterizado, dentre outras estratégias, pela umidificação de coberturas, também é objeto de investigação com comprovado potencial de resfriamento (CAVALCANTI; PRADO, 2001; CAVALCANTI, 2001; LABAKI; TEIXEIRA; TAVARES, 2005; NASCIMENTO, 2005; RORIZ; RORIZ, 2008). Dentre as diferenças em relação ao RED, está o fato de o sistema REI produzir resfriamento sem aumentar a razão de umidade do interior da edificação (SHARIFI; YAMAGATA, 2015), com vantagens sob condições quente-úmidas.

Buscando explorar as vantagens do REI convencional e verificar outros arranjos possíveis, González procedeu a uma bateria de testes com tal sistema (GONZÁLEZ-GARCIA，2010), o qual denomina sistema pasivo de enfriamiento evaporativo indirecto (SPEEI). O conceito desse sistema é o seguinte: ao invés de se molhar uma cobertura convencional, cobre-se os ambientes a serem resfriados com um sistema teto-reservatório, no qual se armazena água. Essa configuração permite aumentar a inércia térmica da edificação com efeito de resfriamento evaporativo, podendose inclusive utilizar-se do resfriamento radiativo noturno. A proposta é resultado de uma série de experimentos (GIVONI, 1984; SÁNCHES, 1993), nos quais, contrariando as expectativas, o SPEEI implantado apresentou bons resultados até mesmo para o clima quente e úmido de Maracaibo, na Venezuela (GONZÁLEZ-GARCIA, 2010).

Dada a qualidade dos resultados obtidos por González, iniciaram-se investigações para a aplicação dessa forma particular de REI sob diferentes condições climáticas brasileiras. A partir da análise do comportamento térmico e de dados do protótipo de uma habitação (Vivienda Bioclimática Prototipo VBP-1) construída em Maracaibo, foram desenvolvidas equações preditivas das temperaturas internas máximas, médias e mínimas. As equações foram aplicadas ao clima de quatro cidades do Nordeste brasileiro (Teresina, Petrolina, Fortaleza e Natal), constatando-se significativa capacidade de redução das temperaturas internas (GONZÁLEZ; KRÜGER, 2013). Mais recentemente, novo estudo teórico baseado nos dados da VBP-1 mostrou que o sistema adapta-se à maior parte do território brasileiro, o que possibilita reduzir o consumo de energia em climatização e melhorar as condições de conforto (GONZÁLEZ; KRÜGER; GIORDANO, 2014). Experimentos utilizando SPEEI, aqui denominados sistemas passivos de resfriamento (SPR), também mostraram bons resultados para a diminuição da temperatura máxima e da amplitude térmica de células-teste na cidade de Florianópolis, de clima temperado subtropical e verão quente (Cfa), de acordo com a classificação de Köppen-Geiger (GONZALEZ et al., 2014).

O presente estudo tem por objetivo reproduzir duas configurações de um REI aplicado a células-teste, possibilitando comparações com resultados obtidos por González em Florianópolis (GONZALEZ et al., 2014), e avaliando-se seu potencial em situação de calor em Curitiba, de clima temperado úmido e verão ameno (tipo $\mathrm{Cfb}$, segundo a classificação de Köppen-Geiger). 


\section{Metodologia}

Os procedimentos utilizados nos experimentos baseiam-se em métodos anteriormente adotados na temática: uso de células-teste em experimentos com resfriamento evaporativo indireto (KRÜGER et al., 2004; KRÜGER; RORIZ, 2004; GONZÁLEZ-GARCIA, 2010; GONZALEZ et al., 2014) e adoção de equações preditivas para a comparação simultânea de diferentes configurações de teste.

As duas hipóteses a serem testadas estão relacionadas ao potencial de utilização do sistema REI. Avalia-se primeiramente a "depressão da temperatura de bulbo úmido" (TBU $\left.\mathrm{Tep}_{\mathrm{de}}\right)$, ou seja, a diferença entre a temperatura de bulbo seco (TBS) e aquela de bulbo úmido (TBU) para o ambiente externo. A TBU dep é um fator psicrométrico definidor do potencial de sistemas baseados na evaporação de água, sendo um indicador relevante do desempenho desses sistemas. Avalia-se também se o volume de água no reservatório em combinação com o alto calor específico do corpo d'água tem importante efeito de aumento da capacidade térmica da cobertura e, em decorrência, da inércia térmica do sistema.

\section{Clima de Curitiba}

A cidade de Curitiba se localiza na Região Sul do Brasil. Possui latitude $25^{\circ} 31^{\prime} \mathrm{S}$, longitude $49^{\circ} 10^{\prime}$ $\mathrm{W}$ e altitude média de $911 \mathrm{~m}$. As normais climatológicas 1961-1990 indicam que no período de verão a média das temperaturas máximas mensais (jan.-mar.) é de $26,3{ }^{\circ} \mathrm{C}$, e a média das temperaturas mínimas é de $16,0{ }^{\circ} \mathrm{C}$. Para esse período, a temperatura máxima absoluta ocorreu em fevereiro de 1975 e foi de $34,8{ }^{\circ} \mathrm{C}$ (INSTITUTO..., 2015). No zoneamento bioclimático brasileiro, a cidade está inserida na zona bioclimática 1 (ABNT, 2003). A carta psicrométrica a seguir apresenta dados do ano climático de referência (Figura 1).

O relatório de saída dos pares de temperatura e umidade do ar para o ano climático aponta para um baixíssimo potencial de aplicação da estratégia de resfriamento evaporativo, sendo este de $1 \%$ das horas do ano ou, para o período diurno apenas (das 6 às 19 horas), de aproximadamente $2 \%$ das horas anuais. Entretanto, sendo o REI em teste em parte responsável por um aumento da capacidade térmica da cobertura, a função do sistema poderia responder ainda pela demanda de aumento de massa térmica para resfriamento; no ano climático, isso corresponderia a um adicional próximo de $2 \%$ das horas anuais, no período diurno, perfazendo dessa forma $4 \%$ para ambas as estratégias.

\section{Módulos experimentais}

Foram confeccionados dois módulos: um MC e um ME, com dimensões idênticas. Utilizou-se compensado naval com $15 \mathrm{~mm}$ de espessura. Para resistir melhor às intempéries ambos receberam como base uma camada de verniz marítimo. Posteriormente, ambos foram pintados com acrílico esmaltado na cor branca. Internamente, as paredes e os pisos foram revestidos com uma camada de $4,5 \mathrm{~cm}$ de poliestireno expandido (EPS).

A diferença entre os módulos está na cobertura. O MC é coberto por uma chapa de compensado naval com $15 \mathrm{~mm}$ de espessura mais $150 \mathrm{~mm}$ de EPS. O ME, em vez de um tamponamento, foi coberto com uma bacia metálica de base quadrada para armazenamento da água.

Figura 1 - Ano climático de referência para Curitiba plotado sobre o diagrama bioclimático da edificação

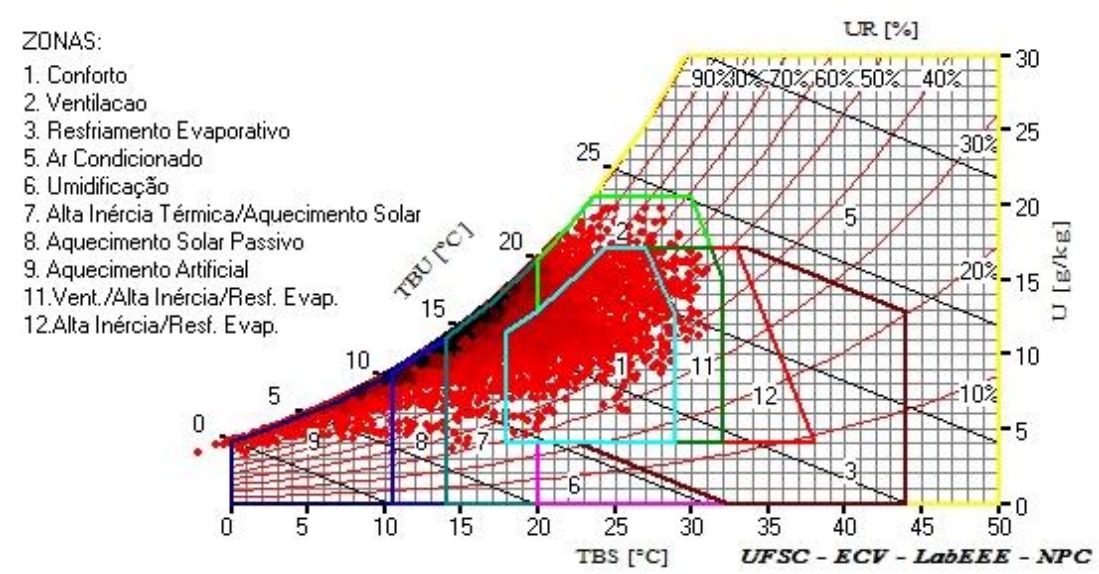

Fonte: Programa Analysis BIO/LabEEE/UFRSC. 
Buscou-se replicar os módulos conforme os confeccionados por González et al. (2014) em seus experimentos 1 e 4 (Exp-1, Exp-4); no entanto, devido às dificuldades durante a execução e visando maior durabilidade dos módulos, ocorreram algumas pequenas diferenças: em vez de madeira compensada simples, utilizou-se compensado naval; em vez de sombrear o ME com chapa de compensado de $15 \mathrm{~mm}$, utilizou-se compensado naval de $10 \mathrm{~mm}$; os módulos originais foram confeccionados com chapas de $18 \mathrm{~mm}$, aqui se utilizou chapas de compensado naval de $15 \mathrm{~mm}$. No entanto, as espessuras das chapas de EPS e o volume de ar interno correspondem aos do experimento original. A alteração na espessura das chapas de compensado levou a uma pequena diferença entre os experimentos em se tratando da transmitância térmica das paredes dos módulos (os módulos de González et al. (2014) apresentam $\mathrm{U}=0,717 \mathrm{~W} /\left(\mathrm{m}^{2} . \mathrm{K}\right), \mathrm{U}=0,717 \mathrm{~W} /\left(\mathrm{m}^{2} . \mathrm{K}\right)$ enquanto os módulos deste experimento apresentam $\mathrm{U}=0,707 \mathrm{~W} /\left(\mathrm{m}^{2} . \mathrm{K}\right) \mathrm{U}=0,707 \mathrm{~W} /\left(\mathrm{m}^{2} . \mathrm{K}\right)$.

A bacia foi confeccionada com chapa de aço galvanizado de espessura 1,2 $\mathrm{mm}$, recebeu ainda uma camada de tinta epóxi para prevenir ferrugem e em seguida foi pintada com tinta acrílica branca. A função da bacia metálica é tornar mais efetivo o processo de resfriamento do ambiente a partir do processo de evaporação da água no reservatório, evitando-se gerar aumento da capacidade térmica do teto-reservatório além do próprio corpo d'água. Para o experimento, a bacia metálica recebeu uma camada de $6,5 \mathrm{~cm}$ de água (o que resultou em um volume total de 29,18 1).

Foram realizadas duas configurações para ME, a primeira com o teto-reservatório (TR) aberto e sombreado (Figura 2).
Nessa configuração, a bacia com água foi sombreada com uma placa de compensado naval de $10 \mathrm{~mm}$ de espessura, envernizada, pintada na cor branca e revestida em sua face inferior com chapa de EPS de $5 \mathrm{~mm}$ de espessura. O espaço de $6 \mathrm{~cm}$ entre a caixa e a placa de sombreamento promove uma ventilação permanente no sistema de evaporação, enquanto o sombreamento garante a não incidência de raios solares diretamente sobre a água. A camada de EPS na face inferior da placa de sombreamento foi adotada para minimizar a transferência de calor a partir da superfície do telhado e da própria "telha" empregada - em uma edificação real, o que se pretende garantir é um ático ventilado com alguma resistência térmica do telhado. $\mathrm{O}$ volume de ar existente internamente em ambas as caixas é o mesmo, $0,14 \mathrm{~m}^{3}$.

Para a configuração 2, TR vedado e isolado, a placa de sombreamento foi substituída por uma tampa de madeira compensada revestida com 4,5 cm de EPS, separada por câmara de ar não ventilada da bacia, que recebeu uma chapa metálica com aplicação de silicone para vedação (Figuras 3 e 4). Nesse caso, ocorre um aumento da capacidade térmica da cobertura no $\mathrm{ME}$ em relação ao MC: para a configuração 2 de $\mathrm{ME}, \mathrm{C}_{\mathrm{T}}=294$ $\mathrm{kJ} /\left(\mathrm{m}^{2} . \mathrm{K}\right)$, enquanto para $\mathrm{MC}$ o valor encontrado foi $\mathrm{C}_{\mathrm{T}}=23 \mathrm{~kJ} /\left(\mathrm{m}^{2} . \mathrm{K}\right)$, ou seja, aumentou-se a capacidade térmica da cobertura em 13 vezes. Em termos de resistência térmica, uma vez que se removeu 2/3 da camada de EPS na configuração 2, incluindo-se em seu lugar uma câmara de ar e um compartimento com água, ambos de baixa resistência térmica, a redução foi de cerca de $60 \%$ em relação ao MC.

Figura 2 - Configuração 1: à esquerda, módulo experimental (ME); e, à direita, módulo de controle (MC)

COMPENSADO NAVAL

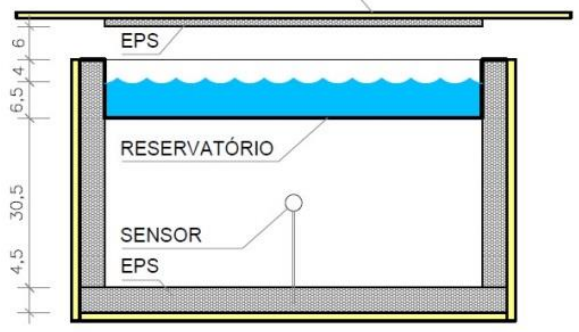

TETO RESERVATÓRIO ABERTO SOMBREADO
COMPENSADO NAVAL EPS

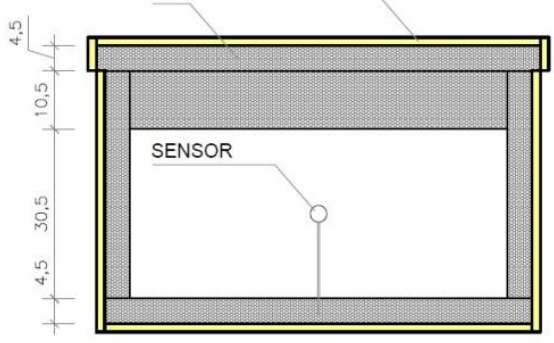

CONTROLE

110 Krüger, E. L.; Lange, S. C.; Fernandes, L.; Rossi, F. 
Figura 3 - Configuração 2: à esquerda, módulo experimental (ME); e, à direita, módulo de controle (MC)
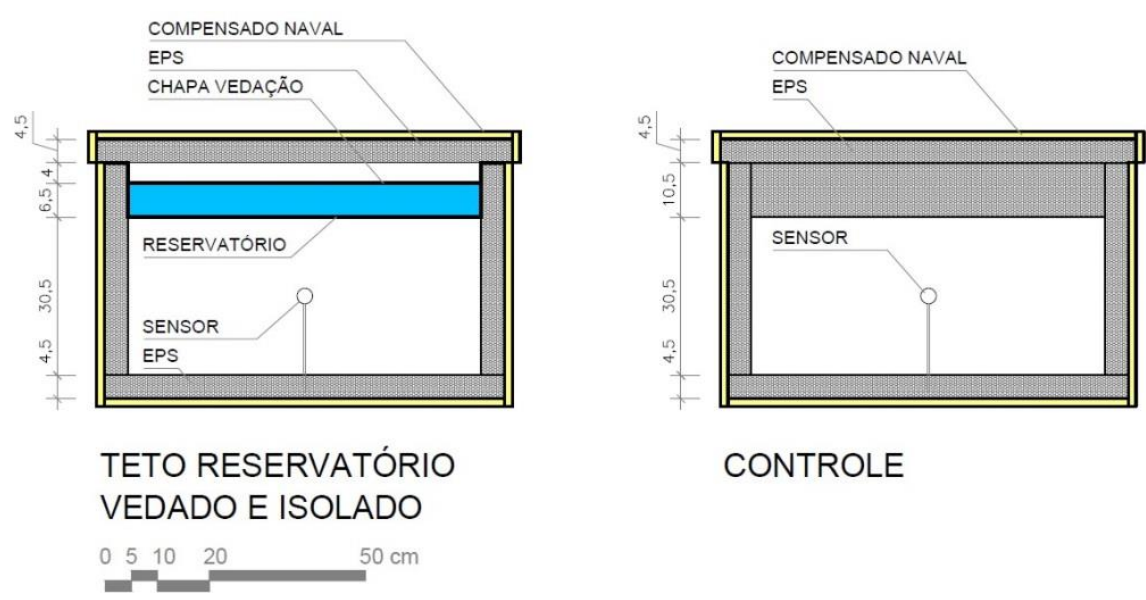

CONTROLE

Figura 4 - Disposição dos módulos ME e MC no local do experimento
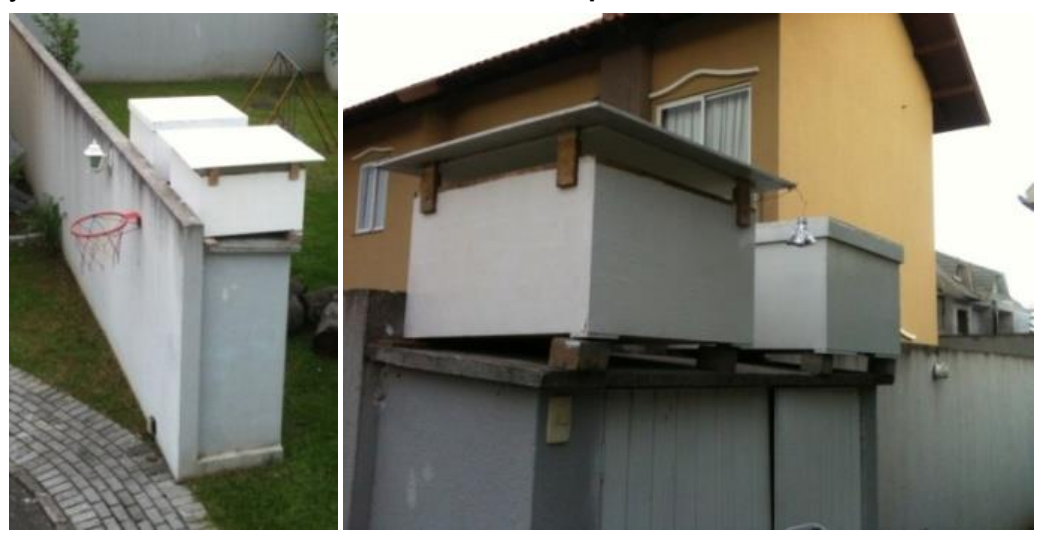

\section{Local do experimento}

O local escolhido para o experimento foi um condomínio residencial na região norte de Curitiba, no bairro de Santa Felicidade. As caixas foram posicionadas de tal forma que pudessem receber a mesma quantidade de radiação solar ao longo do período monitorado e que não projetassem sombras umas sobre as outras. A Figura 5 apresenta detalhes da área e a Figura 6 a incidência solar para os dias médios dos dois períodos de monitoramento.

Durante o experimento, foi realizada diariamente a reposição do nível do reservatório d'água da bacia metálica devido à evaporação. A reposição ocorria pela manhã, antes da incidência dos raios solares, sendo utilizada água à temperatura ambiente.

\section{Aquisição de dados}

O monitoramento da temperatura do ar no local foi feito utilizando três data loggers idênticos da marca Novus, modelo TagTemp-USB. Dois usados para medir as temperaturas internas dos módulos e um para medir a temperatura externa. O sensor desse aparelho opera na faixa de temperaturas de $-20,0{ }^{\circ} \mathrm{C}$ a $70,0{ }^{\circ} \mathrm{C}$, possui tempo de resposta de $5 \mathrm{~s}$ e apresenta precisão de $\pm 0,5^{\circ} \mathrm{C}$ a $25{ }^{\circ} \mathrm{C}$. A umidade relativa local foi registrada utilizando o aparelho LogBox-RHT-LCD, também da marca Novus. O sensor de umidade opera na faixa de $0 \%$ a $100 \%$, possui tempo de resposta de $8 \mathrm{~s}$ em ar em movimento suave (20\% a $80 \%$ UR) e apresenta precisão de $\pm 3 \%$ a $25^{\circ} \mathrm{C}$.

Os aparelhos foram programados para realizar medições a cada 15 min. A configuração dos data loggers e a extração dos dados foi feita com o software FieldChart 1.99.2, da Novus. Visando garantir a uniformidade das medições da temperatura do ar pelos diferentes sensores, estes foram acondicionados em um recipiente de EPS e guardados em um freezer por $24 \mathrm{~h}$ a $-15{ }^{\circ} \mathrm{C}$. Posteriormente foram expostos juntos à temperatura ambiente por mais $24 \mathrm{~h}$ e foram verificadas as diferenças entre as medições registradas, observando-se uma diferença máxima de $0,1^{\circ} \mathrm{C}$ entre os aparelhos, a qual foi considerada aceitável (tal diferença ocorreu apenas em 
temperaturas abaixo de zero, sob as quais não se pretendia testar o sistema), não se necessitando realizar correção dos dados medidos.

O sensor externo de temperatura do ar foi sombreado pela parte superior de uma garrafa PET cortada ao meio, revestida por papel alumínio, e suspensa junto aos módulos. Os sensores internos de temperatura do ar foram posicionados no centro do volume de ar de cada módulo, enquanto o sensor externo de umidade, por não ser à prova d'água, foi posicionado em local sombreado, ventilado, protegido de eventuais chuvas, sob uma laje em edificação próxima.

O período de medições para a configuração 1 abrangeu 24 dias, de 29/10/2014 até 21/11/2014, enquanto para a configuração 2 o período abrangeu 15 dias, de 27/12/2014 até 10/01/2015. A não realização de monitoramentos simultâneos deveuse ao delineamento experimental, o qual previa o teste de oito configurações distintas.

Figura 5 - Implantação dos módulos ME e MC em relação às obstruções do entorno

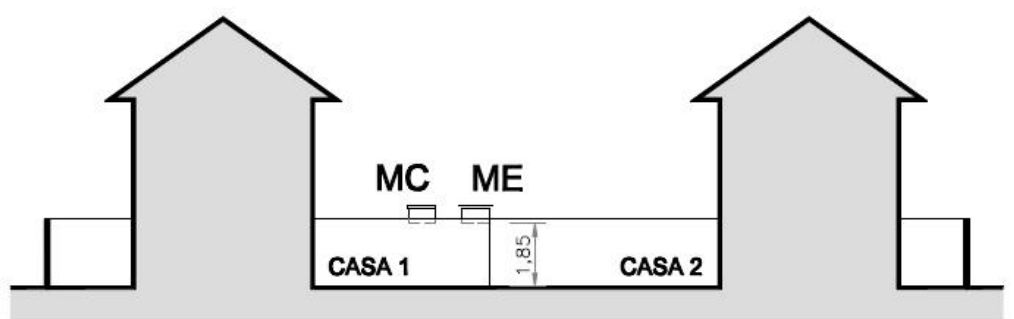

\section{CORTE}

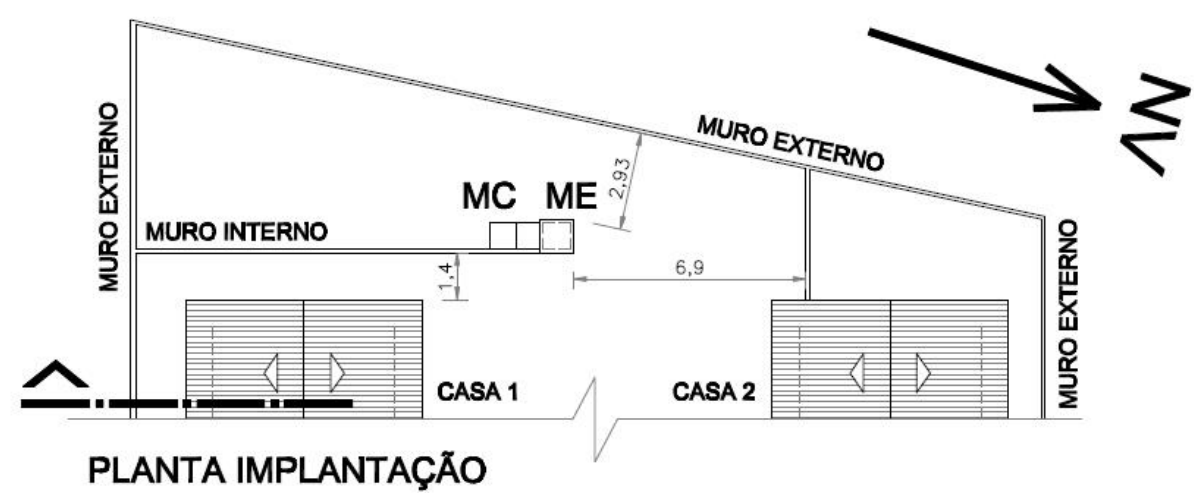

Figura 6 - Estudo da incidência de sombras nos dias 09/11/2014 (fileira superior) e 02/01/2015 (fileira inferior) às 9,12 e 15 horas

Dia 09/11/2014 - $9 \mathrm{~h}$
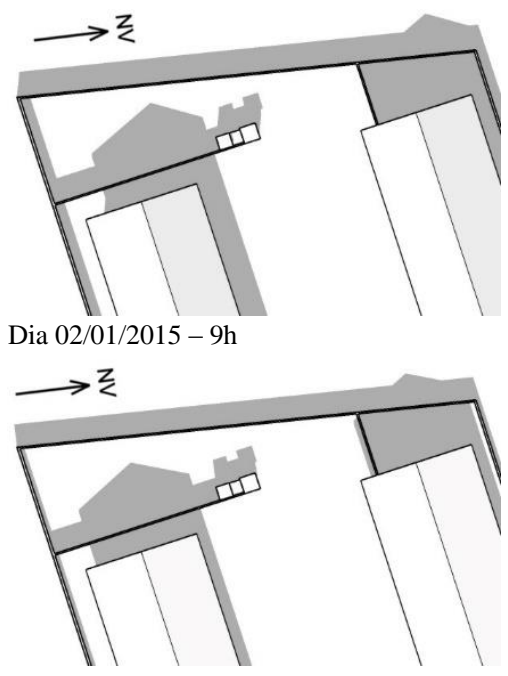

Dia 09/11/2014 - 12h

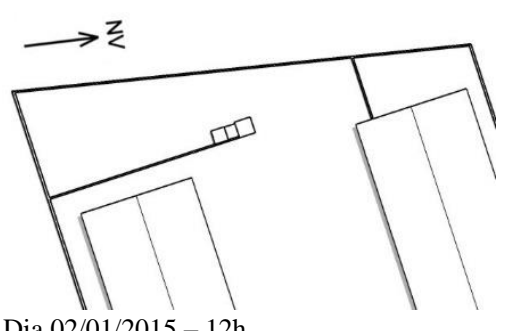

Dia 02/01/2015 - 12h

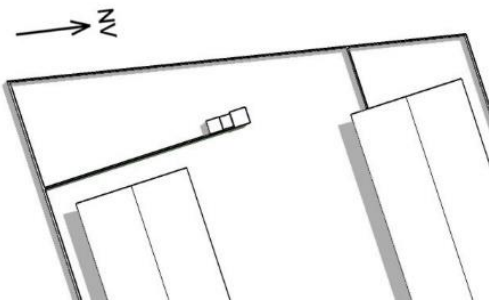

Dia 09/11/2014 - 15h

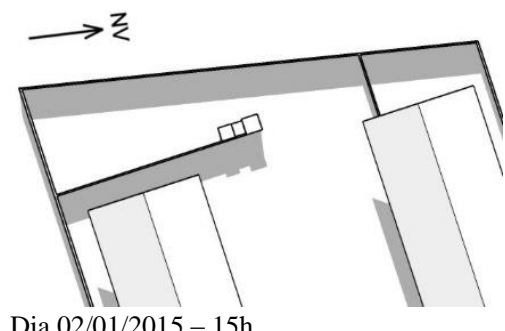

$/ 2015-15 h$

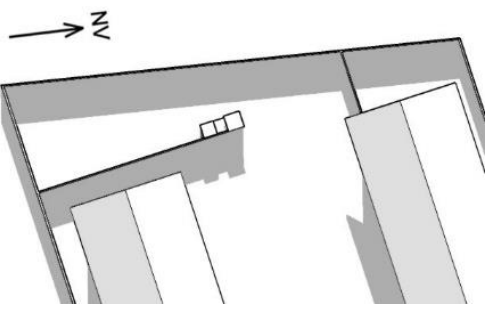

112 Krüger, E. L.; Lange, S. C.; Fernandes, L.; Rossi, F. 


\section{Geração de equações preditivas}

Desenvolveram-se, com base nos dados medidos, equações preditivas do comportamento térmico do ME na configuração 2, para que se pudesse comparar, como procedimento de normalização, sob as mesmas condições climáticas da primeira série de dados o desempenho das duas configurações, relativamente ao MC. A adoção de equações preditivas para estimar temperaturas internas apoia-se em outros estudos com edificações residenciais e protótipos em escala reduzida já realizados (KRÜGER; RORIZ, 2004; PAPST, 2004; FERNANDES, 2005; LIMA, 2009; MONTEIRO, 2013).

Nesta pesquisa, o desenvolvimento das equações preditivas baseou-se no procedimento sugerido por Fernandes et al. (2015). Nesse procedimento considera-se que a temperatura do ar no interior da célula-teste varia, de uma hora para a outra, conforme a diferença em relação à temperatura externa. Na busca de um equilíbrio térmico, há uma tendência de a temperatura interna se aproximar da externa. Isso se dá segundo as características termofísicas do envelope, volume de ar interno, proporção das áreas das superfícies do envelope, entre outros fatores.

Matematicamente, a ideia é que a temperatura interna na hora atual (hora k) é igual à soma da temperatura interna anterior (hora k-1) com a variação observada, e que essa variação se dá proporcionalmente à diferença entre as temperaturas do ar dos dois ambientes, interno e externo (Figura 7).

Expressa-se o modelo conforme a Equação 1:

$$
T_{\text {int }}^{k}=T_{\text {int }}^{k-1}+\alpha\left(T_{\text {ext }}^{k-n}-T_{\text {int }}^{k-1}\right)
$$

Onde:

$T_{i n t}^{k}$ é a temperatura $\left[{ }^{\circ} \mathrm{C}\right]$ estimada no instante $k$; e $\alpha$ é uma função que descreve a variação proporcional da temperatura interna em função da diferença entre $T_{\text {ext }}^{k-n}$ e $T_{i n t}^{k-1}$.

Observa-se que na Equação 1 adotou-se $T_{e x t}^{k-n}$ porque, em cada caso/edificação, é necessário verificar qual temperatura externa utilizar (com defasagem nula $n=0$ para a temperatura atual, $n=1$ para a temperatura defasada em uma unidade hora, nesse caso, e assim por diante).

Os valores da função $\alpha$ determinam como a edificação se relaciona com a temperatura externa, ou seja, correspondem nesse modelo ao que Papst (2004) chamou de assinatura térmica. O valor de $\alpha$ é obtido por meio da Equação 2:

$\alpha=\frac{\Delta T_{i n t}}{T_{e x t}^{k-n}-T_{i n t}^{k-1}} \alpha=\frac{\Delta T_{i n}}{T_{e x}^{k}-T_{i n}^{k-1}} \alpha=\frac{\Delta T_{i n}}{T_{e x}^{k}-T_{i n}^{k-1}} \quad$ Eq. 2

Observa-se que $\alpha$ não é constante, podendo ser representado por uma equação de primeiro ou segundo grau.

Para o desenvolvimento das equações utilizaramse os dados de 27/12/2015 até 02/01/2015. Para a verificação de sua acurácia utilizaram-se os dados de 04/01/2015 até 11/01/2015. Confrontando dados medidos e estimados para o período de 04/01 até 11/01 observou-se que para 50\% das temperaturas estimadas a diferença foi menor que $0,27^{\circ} \mathrm{C}$ (Figura 8 ), a diferença média foi $0,31^{\circ} \mathrm{C}$; a diferença máxima $0,85{ }^{\circ} \mathrm{C}$, e o coeficiente de determinação $\left(\mathrm{R}^{2}\right)$ foi 0,96 .

\section{Figura 7 - Exemplo da variação da da temperatura interna (Tint) como uma fração da diferença entre} exterior e interior (Text e Tint)

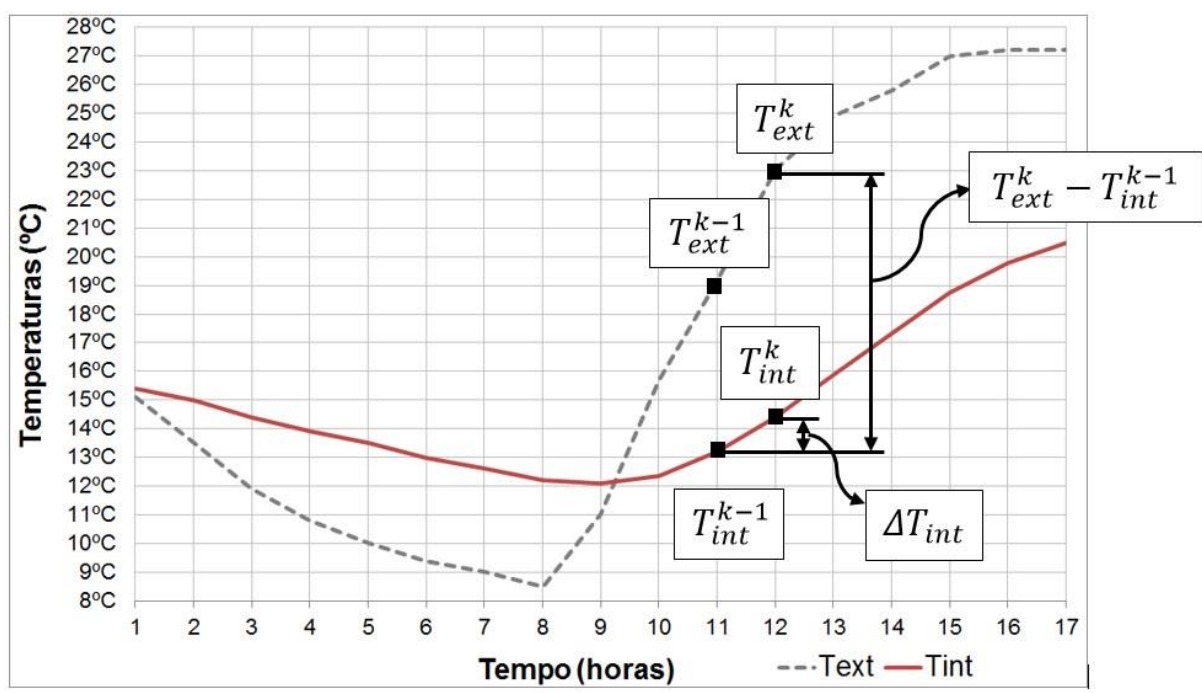


Figura 8 - Histograma da diferença entre temperaturas estimadas e medidas e gráfico de dispersão (temperaturas medidas $\times$ estimadas)
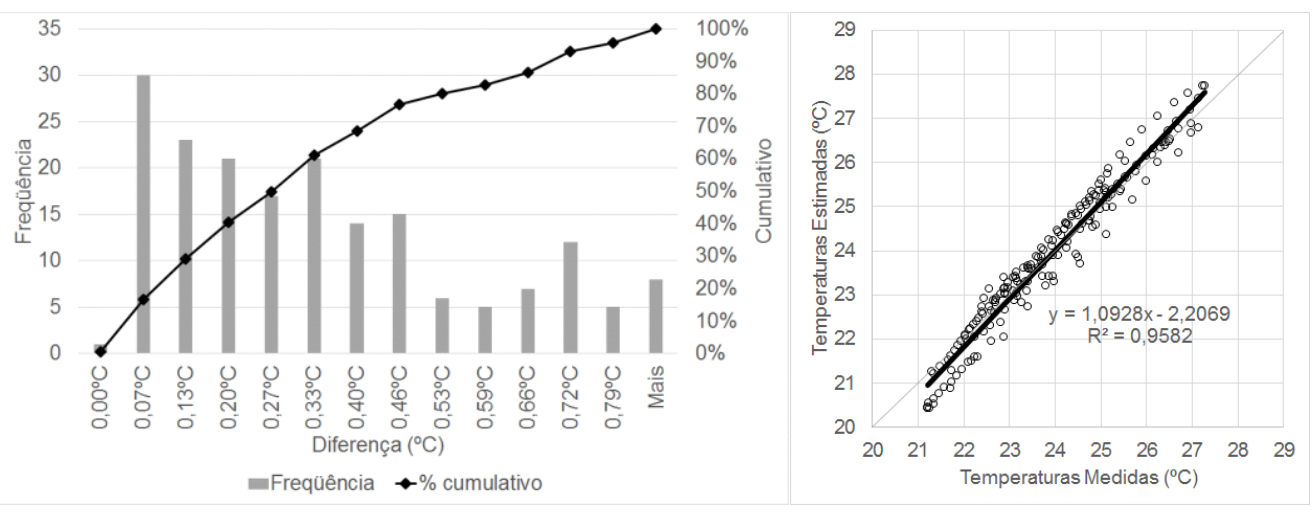

Diante dos resultados encontrados, considerou-se o modelo adequado para estimativa do comportamento térmico da configuração 2 no período de 29/10/2014 até 21/11/2014, correspondente à configuração 1 , o que possibilitou comparar o desempenho das diferentes configurações utilizadas para o ME. Novamente, ressalta-se que, segundo o planejamento experimental, estavam previstos testes com diversas configurações do sistema - em função desse planejamento, adotou-se o procedimento clássico de se trabalhar com "módulo controle" versus "módulo experimental". A utilização do método preditivo se deu em razão de os dois períodos monitorados terem apresentado diferentes condições de nebulosidade. Dessa forma, os dados referenciais do $\mathrm{MC}$, afetados pelas condições climáticas diferentes (e divergentes) nas duas etapas de monitoramento, tiveram de ser normalizados para uma comparação direta. Adotou-se a primeira etapa de monitoramento para a comparação direta, estimando-se os resultados da configuração 2 do $\mathrm{ME}$ para as condições climáticas de baixa nebulosidade da primeira etapa.

\section{Analise dos resultados}

\section{Teto-reservatório aberto e sombreado (configuração 1)}

A Figura 9 apresenta os dados internos medidos nos dois módulos comparativamente às condições de temperatura e umidade externas. A temperatura externa variou no período entre $11,8{ }^{\circ} \mathrm{C}$ e $34,5^{\circ} \mathrm{C}$, com correspondente variação na umidade relativa. O MC acompanha o padrão das temperaturas externas, sem mostrar nem amortecimento térmico nem efeito de atraso térmico e um sobreaquecimento de aproximadamente $2{ }^{\circ} \mathrm{C}$ nos dias com temperatura mais elevada. O ME com TR aberto e sombreado mostra ambos os efeitos: amortecimento e atraso térmicos, com significativa diferença para as temperaturas internas medidas no MC.

A diferença térmica nos módulos quanto às condições exteriores ( $\mathrm{T}_{\text {ext }}-\mathrm{MC}$ e $\left.\mathrm{T}_{\mathrm{ext}}-\mathrm{ME}\right)$ varia fortemente durante o ciclo de $24 \mathrm{~h}$, é pouco nítida durante $o$ período noturno e extremamente acentuada no período diurno (Figura 10) diferenças positivas apontam para o resfriamento das condições do ar. A Tabela 1 mostra as diferenças relativas entre $\mathrm{MC}$ e $\mathrm{ME}$ e entre ambos relativamente às condições externas vigentes (médias com amplitude observada, médias das mínimas e máximas diárias); as diferenças térmicas (Delta T's) são expressas como dados médios e médias dos valores mínimos e máximos, para cada dia de medição.

A diferença térmica encontrada entre ambos os módulos mostra o benefício do sistema em relação ao caso-base sem aplicação dele. A amplitude térmica (valores absolutos) para o período atingiu $14,1{ }^{\circ} \mathrm{C}$ para o $\mathrm{ME}$, enquanto para o $\mathrm{MC}$ foi de $26,2{ }^{\circ} \mathrm{C}$ e, no ambiente externo, chegou a $22,7{ }^{\circ} \mathrm{C}$. Dessa forma, no MC ocorreu um aumento de $15 \%$ da amplitude térmica externa; analogamente, no ME deu-se uma redução na amplitude térmica de quase $40 \%$.

Uma vez que o sistema empregado no ME é baseado no resfriamento evaporativo, o principal fator climático definidor de seu potencial é a denominada "depressão da temperatura de bulbo

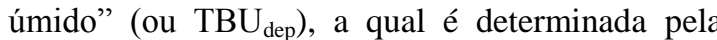
diferença entre a temperatura de bulbo seco (TBS) e aquela de bulbo úmido (TBU). Quanto maior for a $\mathrm{TBU}_{\mathrm{dep}}$, maior será o resfriamento evaporativo, ou seja, quanto mais seco o ar, maior o potencial evaporativo, sendo maior a queda da temperatura interna esperada. Givoni (1992) sugere que o potencial de um sistema de resfriamento direto seja em torno de $70-80 \%$ da TBU $_{\text {dep. }}$. Erell (2007)

114 Krüger, E. L.; Lange, S. C.; Fernandes, L.; Rossi, F. 
comenta que em sistemas evaporativos o limite de temperatura interna a ser atingido seria dado pelo valor da TBU, porém em geral esse valor não chega a ser atingido. Sistemas de resfriamento evaporativo demonstram comumente temperaturas em torno de $2{ }^{\circ} \mathrm{C}$ acima da TBU. Assume-se que, em sistemas indiretos, tal potencial seria mais reduzido.

Com base nos dados medidos de temperatura do ar e umidade relativa, foi obtida por psicrometria algebricamente a temperatura de bulbo úmido para as condições externas, a partir da qual foram calculados os valores de $\mathrm{TBU}_{\text {dep }}$ (Tabela 2).

Figura 9 - Evolução das temperaturas do ar (interna e externa) e umidade relativa externa medidas para a configuração 1 do "ME"

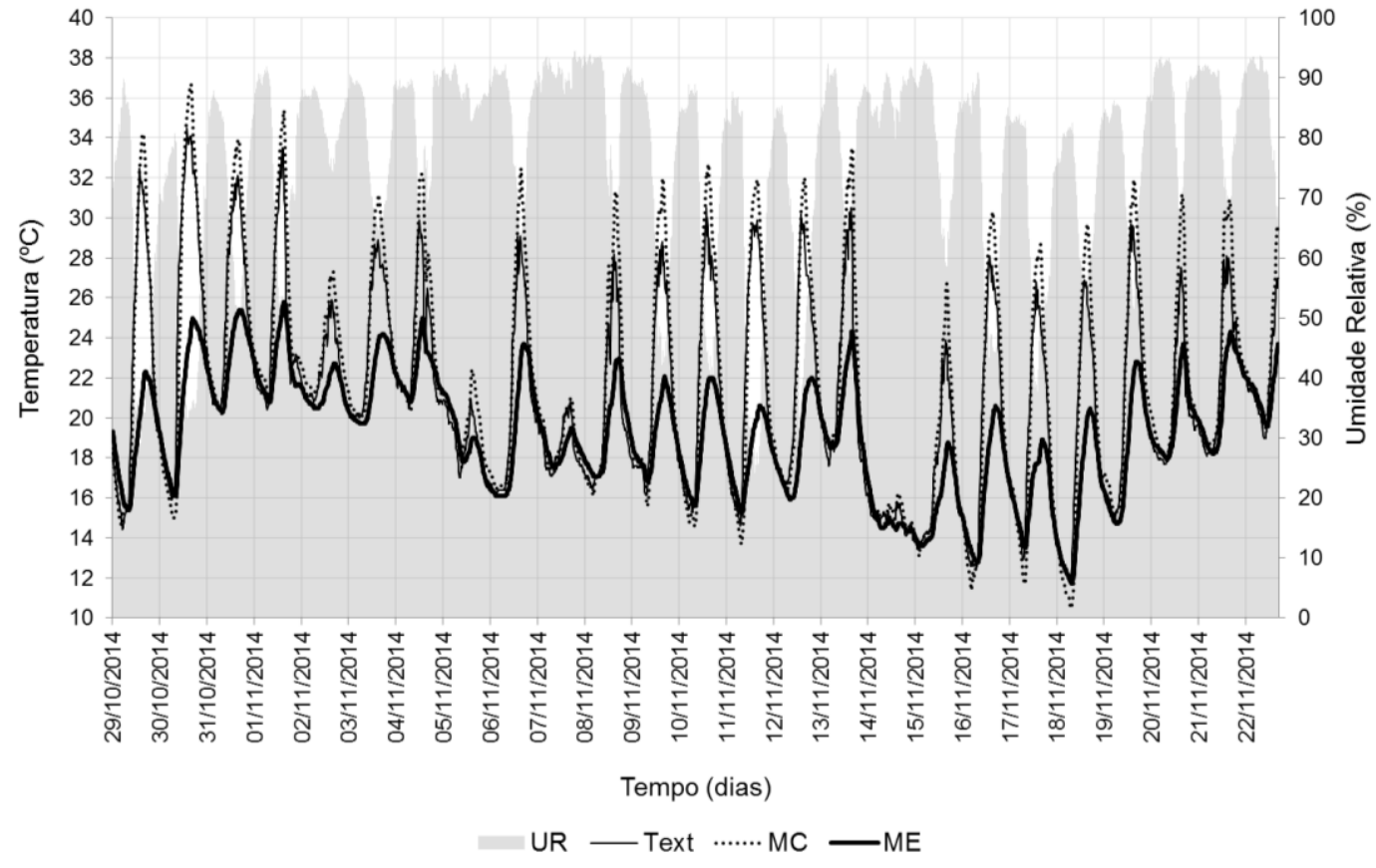

Figura 10 - Diferenças térmicas entre $M C$ e ME relativamente à temperatura externa para um dia de céu claro (em 21/11/2014)

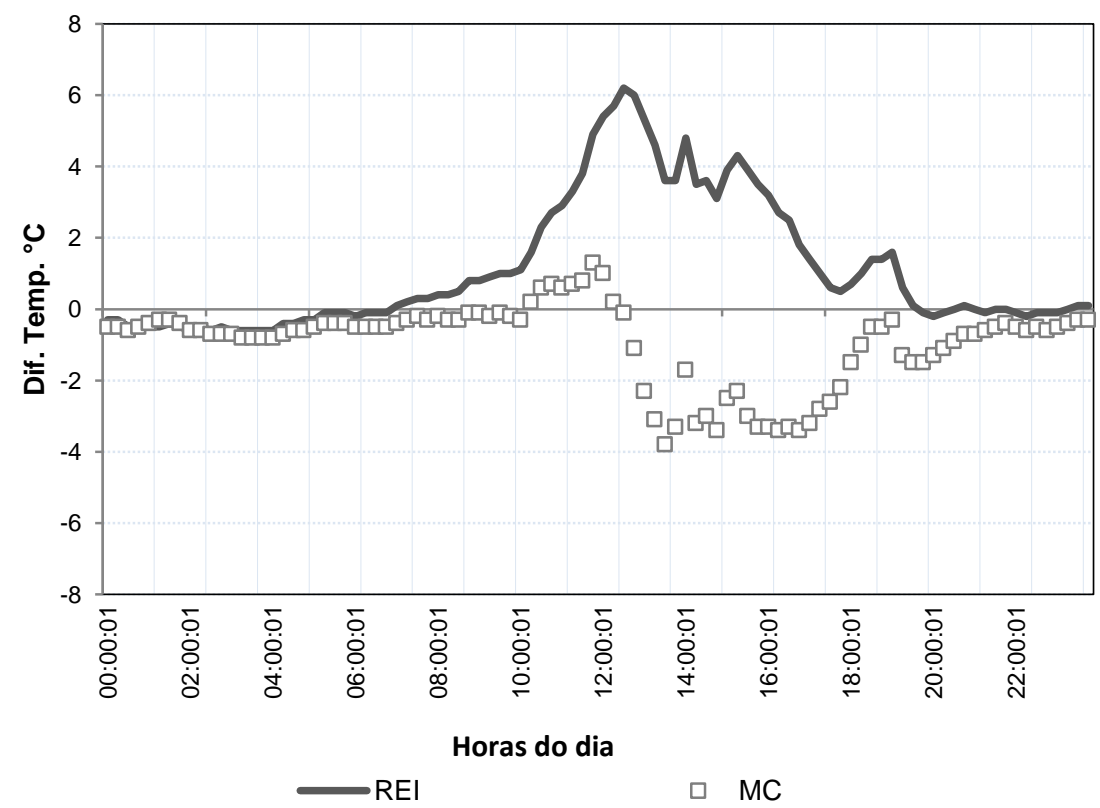


Tabela 1 - Valores medidos encontrados para o período, diferenças em termos de temperatura do ar $\left({ }^{\circ} \mathrm{C}\right)$ encontradas nos dois módulos e em relação ao exterior

\begin{tabular}{|c|c|c|c|c|c|c|c|c|}
\hline & $\mathbf{T}_{\text {ext }}$ & $\begin{array}{c}\mathbf{T}_{\text {int }} \\
(\mathbf{M C})\end{array}$ & $\begin{array}{c}\mathbf{T}_{\text {int }} \\
(\mathbf{M E})\end{array}$ & $\begin{array}{c}\text { DeltaT } \\
\text { (MC-ME) } \\
24 h\end{array}$ & $\begin{array}{c}\text { DeltaT } \\
\text { (MC-ME) } \\
\text { noite }\end{array}$ & $\begin{array}{c}\text { DeltaT } \\
\text { (MC-ME) } \\
\text { Dia }\end{array}$ & $\begin{array}{c}\text { DeltaT } \\
\left(T_{\text {ext }}-M E\right) \\
\text { dia }\end{array}$ & $\begin{array}{c}\text { DeltaT } \\
\left(\mathrm{T}_{\text {ext }}-\mathrm{MC}\right) \\
\text { dia }\end{array}$ \\
\hline $\begin{array}{l}\text { Média e } \\
\text { amplitude }\end{array}$ & $\begin{array}{c}21,1 \\
11,8-34,5\end{array}$ & $\begin{array}{c}21,7 \\
10,5-36,7\end{array}$ & $\begin{array}{c}19,2 \\
11,7-25,8\end{array}$ & 2,6 & 0,3 & 4,4 & 3,6 & $-0,8$ \\
\hline $\begin{array}{l}\text { Média das } \\
\text { máximas }\end{array}$ & 28,1 & 30,3 & 22,3 & 8,4 & 2,2 & 8,7 & 7,3 & 2,1 \\
\hline $\begin{array}{l}\text { Média das } \\
\text { mínimas }\end{array}$ & 16,4 & 16,2 & 16,6 & $-0,7$ & $-0,5$ & $-0,3$ & $-0,5$ & $-3,7$ \\
\hline
\end{tabular}

Tabela 2 - Valores encontrados de $\operatorname{TBU}_{\text {dep }}$ e TBU $\left({ }^{\circ} \mathrm{C}\right)$

\begin{tabular}{lcccc}
\hline & TBU & TBU $_{\text {dep }}$ & TBU $_{\text {dep }}$ (noite) & TBU $_{\text {dep }}$ (dia) \\
\hline Média & 18,5 & 2,6 & 1,2 & 3,7 \\
Máximo & 22,2 & 6,6 & 2,7 & 6,6 \\
Mínimo & 15,4 & 0,6 & 0,6 & 0,7 \\
\hline
\end{tabular}

Como se vê (cf. Tabela 1), a temperatura interna média medida em ME se situa em torno de $1{ }^{\circ} \mathrm{C}$ acima da TBU média para o período monitorado, estando a média das máximas diárias apenas 0,1 ${ }^{\circ} \mathrm{C}$ acima da TBU máxima diária (média do período).

A Figura 11 mostra a correlação encontrada entre a diferença entre $\mathrm{ME} \mathrm{e} \mathrm{T}_{\text {ext }}$ e entre $\mathrm{MC}$ e $\mathrm{T}_{\text {ext }}$, versus $\mathrm{TBU}_{\mathrm{dep}}$, para o período diurno, no qual se nota que, de forma consistente, a $\mathrm{TBU}_{\mathrm{dep}}$ é um forte definidor do potencial de resfriamento de ME, enquanto o MC não apresenta nenhum relação significativa com a variável $\mathrm{TBU}_{\mathrm{dep}}$, uma vez que não se utiliza desse processo de resfriamento.

$\mathrm{O}$ potencial de resfriamento encontrado no TR aberto e sombreado para o período diurno chegaria no máximo a $12,4{ }^{\circ} \mathrm{C}$ (limite teórico dado pela $\mathrm{TBU}_{\text {dep }}$ máxima absoluta medida no período). O DeltaT ( $\left.\mathrm{T}_{\text {ext }}-\mathrm{ME}\right)$ máximo encontrado atinge em média $7,3{ }^{\circ} \mathrm{C} \quad\left(\sim 60 \%\right.$ de redução da $\mathrm{TBU}_{\mathrm{dep}}$ máxima), sendo esse resultado consistente com a estimativa de Givoni para sistemas RED, embora se deva considerar que se trata de um sistema REI. Por outro lado, os valores médios obtidos indicam um potencial de resfriamento máximo para o período diurno (em média) de $6,6{ }^{\circ} \mathrm{C}$, ou seja, inferior ao observado, $7,3{ }^{\circ} \mathrm{C}$. Considerando o que foi observado anteriormente quanto à temperatura média interna encontrada em ME estar muito próxima da TBU média para o período monitorado, esse desempenho fica acima do valor sugerido por Erell. Dessa forma, supõe-se que o efeito do aumento de capacidade térmica da cobertura pela adição de $6,5 \mathrm{~cm}$ de lâmina d'água tenha contribuído significativamente para o alto desempenho do sistema. A massa de água mantémse em temperatura mais constante (resultante de seu alto calor específico), o que, associado à alta condutividade da bacia metálica, resulta que o $\mathrm{ME}$ acompanhe a pequena variação da temperatura da água do reservatório. Assim, no período da noite, a temperatura da água tende a acompanhar a temperatura externa (com TBS $\approx \mathrm{TBU}$ ) e, durante o dia, a temperatura da água tende a ser limitada pela TBU.

\section{Coeficiente de Performance (COP) e Potencial de Resfriamento Médio (PRM)}

O desempenho de um sistema passivo pode ser avaliado considerando seu diferencial relativamente ao caso-base (ausência do sistema passivo) e, no caso de sistemas de resfriamento evaporativo, levando-se em conta a TBU $\mathrm{Tep}_{\text {, }}$ segundo a relação dada pela Equação 3 (KRÜGER; GONZÁLEZ CRUZ; GIVONI, 2010):

$C O P=\frac{T_{\text {int (sem resfriamento })}-T_{\text {int }(\text { com resfriamento })}}{T B U_{\text {dep }}} \quad$ Eq. 3

Para o período monitorado, o coefficient of performance (COP) foi obtido com os dados médios diários, gerando valores de COP acima de 100\% (Figura 10), ou seja, um desempenho acima do que seria fisicamente possível com um sistema REI. Sendo assim, é de se supor mais uma vez que o ME se beneficia não apenas do efeito de resfriamento evaporativo, porém também do efeito de aumento da capacidade térmica da cobertura. Para os dias de condições mais estáveis, de maior amplitude térmica externa (HOLMER; THORSSON; LINDÉN, 2013), aqui se considerando valores acima de $10^{\circ} \mathrm{C}$ de flutuação térmica diária, o atraso térmico verificado para o ME foi de aproximadamente $15 \mathrm{~min}$ (em MC, o atraso foi de cerca de $20 \mathrm{~min}$ ). 
Figura 11 - Correlação encontrada entre diferenças: (a) entre a temperatura externa e interna em ME e a depressão da temperatura do bulbo úmido; e (b) entre a temperatura externa e interna em $M C$ e a depressão da temperatura do bulbo úmido, para o período diurno

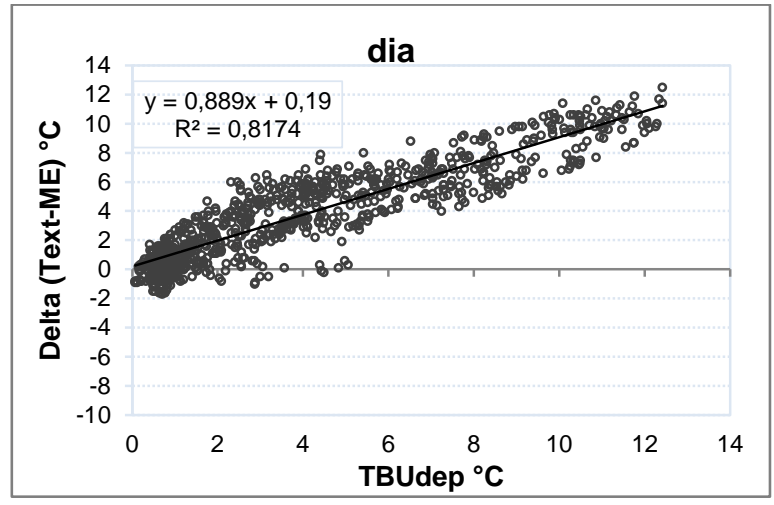

(a)

Comparativamente aos experimentos apresentados por Gonzalez et al. (2014) em Florianópolis (ZB 3), o experimento 1 realizado por esses autores, com modulação das células-teste e configurações bastante similares às do presente experimento, teve como resultado uma redução da temperatura interna de até $10,4{ }^{\circ} \mathrm{C}$ em relação à externa (máximas diárias). A diferença máxima diária encontrada no experimento ora realizado foi em média de $7,3{ }^{\circ} \mathrm{C}$, o que torna os resultados coerentes com os relatados por Gonzalez et al. (2014), considerando-se a situação climática de Curitiba. Observou-se, igualmente, que as mínimas internas foram próximas às externas, tanto para MC como para ME.

González e González-Maciel (2013), em pesquisa anterior segundo o mesmo delineamento experimental, porém para Maracaibo, Venezuela, apresentam o índice potencial de resfriamento médio (PRM), definido como "[...] la cantidad de energía por unidad de tiempo y de superficie, capaz de ser retirada por el sistema, obtenida como valor medio durante un periodo de 24 horas [...]" (GONZÁLEZ, 1997, p. 214), Equação 4.

$P R M=$

$\frac{C P C . T_{\text {med (módulo de controle })}-T_{\text {med (módulo experimental) }}}{A}$

Eq. 4

Onde:

CPC é o coeficiente de perda de calor do módulo $\left(\mathrm{W} /{ }^{\circ} \mathrm{C}\right)$;

$\mathrm{T}_{\text {med }}$ é a temperatura média diária dos dois módulos (MC e ME, no caso) $\left({ }^{\circ} \mathrm{C}\right)$; e

e A é a área efetiva de superfície da cobertura $\left(\mathrm{m}^{2}\right)$.

Adotando-se $\mathrm{CPC}=1,50 \mathrm{~W} /{ }^{\circ} \mathrm{C}$ e a superfície de cobertura $A=0,462 \mathrm{~m}^{2}$, como fizeram Gonzalez et al. (2014) para Florianópolis e Maracaibo, pôde-se

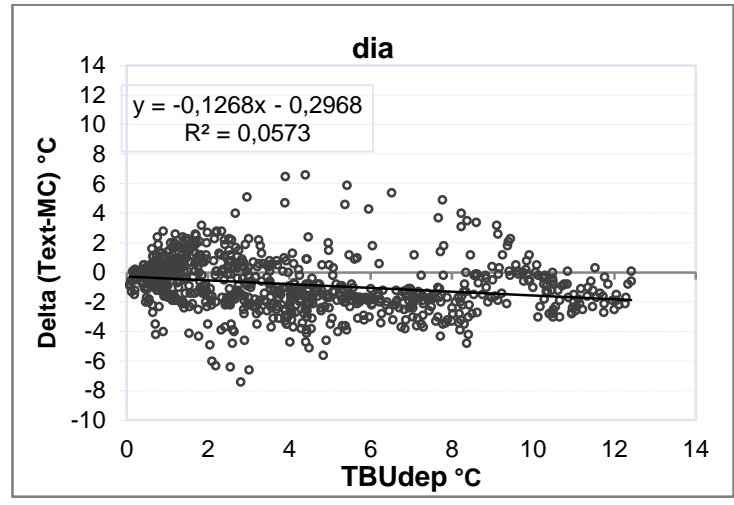

(b)

obter o PRM, dado em $\mathrm{Wh} / \mathrm{m}^{2}$.dia e sua variação ao longo dos 24 dias de experimento. A Figura 12 apresenta valores calculados de COP e PRM, dia a dia. Os valores de PRM se assemelham aos obtidos no experimento 3 referido por Gonzalez e Gonzalez-Garcia (2013), para Maracaibo, e ao valor máximo citado para o mesmo índice por Gonzalez et al. (2014), de $286 \mathrm{Wh} / \mathrm{m}^{2}$.dia, para Florianópolis. Com alguma variação, como, por exemplo, para os dias 7 e 14 de novembro, em que ocorreu uma queda brusca de temperatura e a umidade relativa permaneceu alta, o valor médio se aproxima de $200 \mathrm{Wh} / \mathrm{m}^{2}$.dia, e o pico verificado para o período foi de $337 \mathrm{Wh} / \mathrm{m}^{2}$.dia, o qual se obteve para o dia com maior amplitude térmica da temperatura externa e a maior $\mathrm{TBU}_{\mathrm{dep}}$ do período de monitoramento. Assumindo a amplitude térmica diária $\left(\mathrm{T}_{\max }-\mathrm{T}_{\min }\right)_{24 \mathrm{~h}}$ como possível indicador da estabilidade atmosférica diária, notase que esse fator é fundamental para o desempenho do sistema.

\section{Condições de conforto térmico: potencial de resfriamento}

A representatividade da estratégia de resfriamento evaporativo no período monitorado pode ser verificada com a plotagem dos pares de temperatura e umidade do ar externas sobre a carta bioclimática de Givoni, contemplando-se mais uma vez apenas o período diurno (Figura 13). O relatório de saída fornece uma demanda de 11,5\% do período diurno por resfriamento evaporativo. Somando-se massa térmica para resfriamento (zonas 4 e 11 do diagrama), como mencionado acima, importante subproduto do sistema REI implementado, a demanda total pelas duas estratégias atinge cerca de $25 \%$ das horas diurnas monitoradas. 
Figura 12 - Valores do Coefficient of Performance (COP) e do Potencial de Resfriamento Médio (PRM) para os 24 dias de experimento

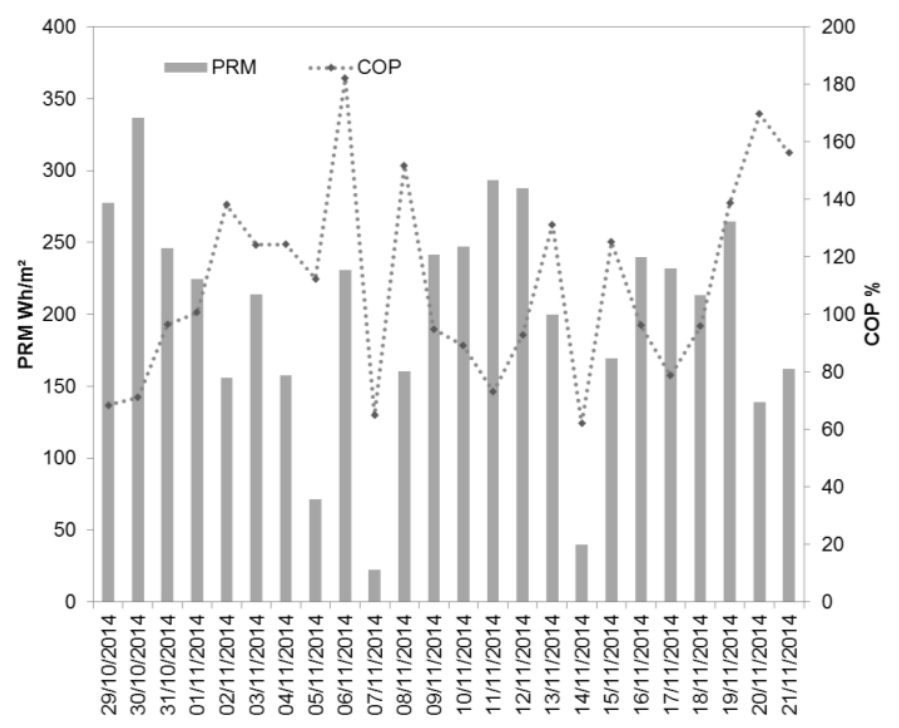

Figura 13 - Valores medidos de temperatura e umidade externas sobre o diagrama bioclimático da edificação - Período diurno

e

ZONAS:

1. Conforto

2. Ventilacao

3. Restriamento Evaporativo

4. Massa Térmica p/ Restr.

5. Ar Condicionado

6. Umidificação

7. Massa Térmica/Aquecimento Solar

8. Aquecimento Solar Passivo

9. Aquecimento Artificial

10.Ventilacão/Massa

11.Vent./Massa/Rest. Evap.

12. Massa/Riesf. Evap.

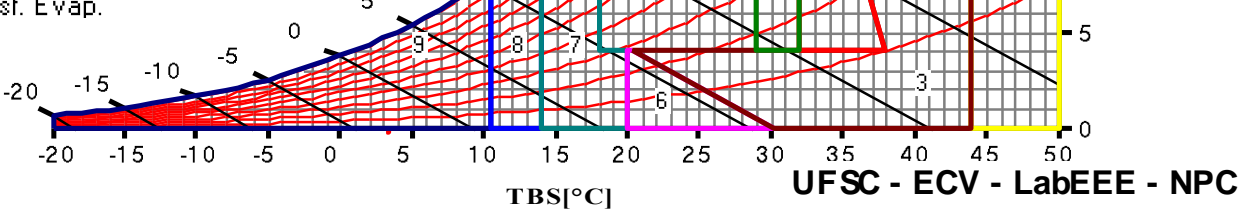

Para essas condições, a vantagem em termos de aumento dos níveis de conforto/diminuição da necessidade de resfriamento pode ser testada ao se comparar o somatório de graus/hora obtido para determinada temperatura-base, calculado para as condições externas e internas (MC versus ME). Como se trata de um sistema passivo, pode-se adotar o limite de temperatura de conforto adaptativo com base na norma ASHRAE Standard 55, indicada para edificações ventiladas naturalmente (DE DEAR; BRAGER, 2002). De acordo com essa norma, a temperatura de conforto $\left(\mathrm{T}_{\text {conf }}\right)$ é determinada com base na temperatura média mensal externa, conforme a Equação 5:
$T_{\text {conf }}=17,8+0,31 \cdot T_{\text {med-ext }}$

Eq. 5

Onde $\mathrm{T}_{\text {med-ext }}$ é a temperatura média do mês.

Adotando-se como $\mathrm{T}_{\text {med-ext }}$ a temperatura média registrada no local para o período monitorado (cf. Tabela 1), obtém-se $24,3{ }^{\circ} \mathrm{C}$ como temperatura de conforto. Calculando-se o somatório de diferenças de temperatura acima dessa temperatura-base, obtém-se então um total de $493,2{ }^{\circ} \mathrm{C} . h$ para o ambiente externo, $772,7^{\circ} \mathrm{C} . \mathrm{h}$ para $\mathrm{MC}$ e apenas $10,9^{\circ} \mathrm{C} . h$ para ME. Ou seja, se essa diferença para a temperatura-base fosse constante e de $1{ }^{\circ} \mathrm{C}$, terse-ia mais de $96 \%$ das horas diurnas do período monitorado $(336 \mathrm{~h})$ sem desconforto por calor/necessidade de resfriamento em ME. 


\section{Teto-reservatório vedado e isolado (configuração 2)}

A Figura 14 apresenta os dados internos medidos nos dois módulos, para essa segunda configuração, comparativamente às condições de temperatura $\mathrm{e}$ umidade externas. A temperatura externa variou no período entre $18,5{ }^{\circ} \mathrm{C}$ e $33,6{ }^{\circ} \mathrm{C}$, com correspondente variação na umidade relativa. $\mathrm{O}$ MC acompanha o padrão das temperaturas externas, tal qual na configuração 1 , sem mostrar nem amortecimento térmico nem efeito de atraso térmico e um sobreaquecimento de cerca de $2{ }^{\circ} \mathrm{C}$ nos dias com temperatura mais elevada. $\mathrm{O} \mathrm{ME}$, agora com TR vedado e isolado, mostra ambos os efeitos: amortecimento e atraso térmico tanto para as temperaturas altas quanto para as baixas, mostra redução na amplitude térmica e apresenta também significativa diferença para as temperaturas internas medidas no MC.

A diferença térmica nos módulos varia fortemente durante o ciclo de $24 \mathrm{~h}$, é também percebida no período noturno (ME) e mostra-se extremamente acentuada no período diurno (Figura 15 e Tabela $3)$. Figura 14 - Evolução das temperaturas do ar (interna e externa) e umidade relativa externa medidas
para a configuração 2 do "ME"

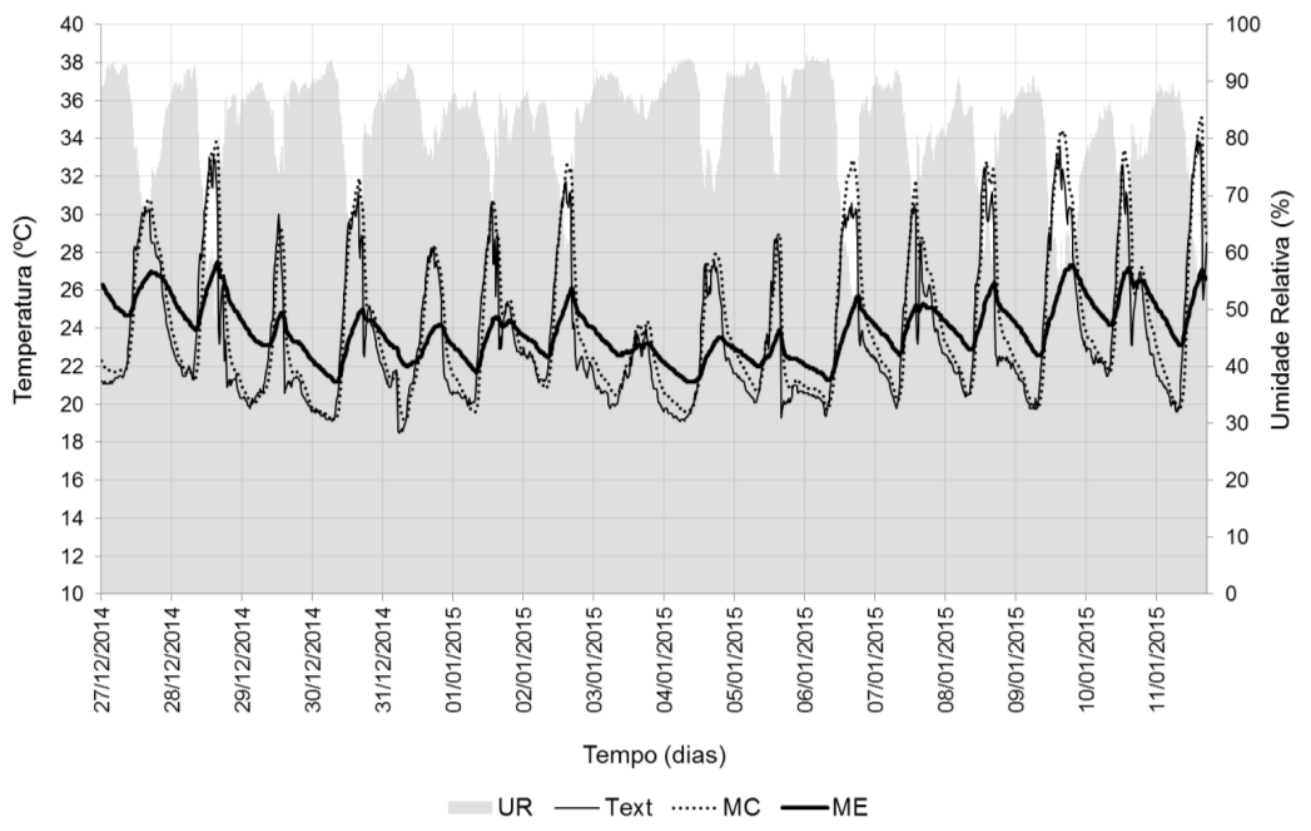

Figura 15 - Diferenças térmicas entre $M C$ e ME relativamente à temperatura externa para um dia de céu claro (em 9/01/2015)

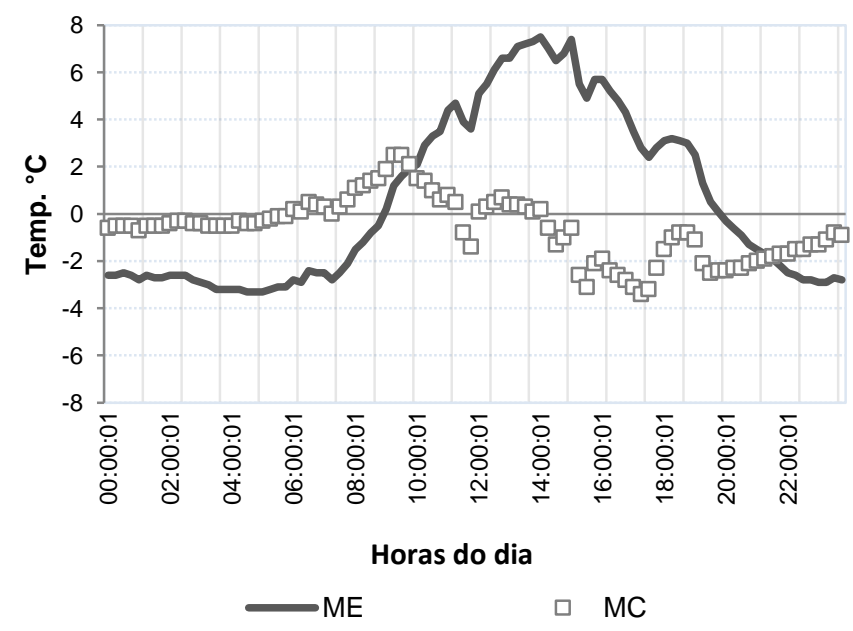


Tabela 3 - Valores medidos encontrados para o período, diferenças em termos de temperatura do ar $\left({ }^{\circ} \mathrm{C}\right)$ encontradas nos dois módulos e em relação ao exterior

\begin{tabular}{lcccccccc}
\hline & $\mathbf{T}_{\text {ext }}$ & $\begin{array}{c}\mathbf{T}_{\text {int }} \\
(\mathbf{M C})\end{array}$ & $\begin{array}{c}\mathbf{T}_{\text {int }} \\
(\mathbf{M E})\end{array}$ & $\begin{array}{c}\text { DeltaT } \\
(\mathbf{M C}-\mathbf{M E}) \\
\mathbf{2 4 h}\end{array}$ & $\begin{array}{c}\text { DeltaT } \\
(\mathbf{M C}-\mathbf{M E}) \\
\text { noite }\end{array}$ & $\begin{array}{c}\text { DeltaT } \\
(\mathbf{M C}-\mathbf{M E}) \\
\mathbf{d i a}\end{array}$ & $\begin{array}{c}\text { DeltaT } \\
\left(\mathbf{T}_{\text {ext }}-\mathbf{M E}\right) \\
\text { dia }\end{array}$ & $\begin{array}{c}\text { DeltaT } \\
\left(\mathbf{T}_{\text {ext }}-\mathbf{M C}\right) \\
\text { dia }\end{array}$ \\
\hline Média e & 23,6 & 24,1 & 23,9 & & & & & \\
amplitude & $18,5-$ & $19,2-$ & $21,2-$ & 0,2 & $-1,5$ & 1,6 & 1,2 & $-0,4$ \\
& 33,6 & 34,4 & 27,5 & & & & & \\
Máximo & 30,4 & 30,9 & 25,5 & 3,8 & 0,4 & 3,8 & 3,6 & 1,4 \\
Mínimo & 19,9 & 20,3 & 22,5 & $-1,7$ & $-1,6$ & $-1,5$ & $-2,1$ & $-3,4$ \\
\hline
\end{tabular}

A diferença térmica encontrada entre ambos os módulos mostra o benefício do TR vedado e isolado em relação ao caso-base (MC). A massa térmica gerou um significativo atraso térmico e, consequentemente, uma redução da temperatura interna de $\mathrm{ME}$ durante o dia, que chegou a um máximo de $8,1{ }^{\circ} \mathrm{C}$ abaixo do $\mathrm{MC}$ e manteve a temperaturas mais elevada durante a noite, situando-se em média $1,5{ }^{\circ} \mathrm{C}$ acima do caso-base. A amplitude térmica para o período foi de apenas $6,3{ }^{\circ} \mathrm{C}$ para o ME, enquanto para o MC foi de 15,2 ${ }^{\circ} \mathrm{C}$ e externamente chegou a $15,1^{\circ} \mathrm{C}$. Dessa forma, o ME atinge uma redução da amplitude térmica no período de aproximadamente $60 \%$

Como essa configuração empregada para o sistema (ME) não se baseia no resfriamento evaporativo, a "depressão da temperatura de bulbo úmido" (ou $\mathrm{TBU}_{\mathrm{dep}}$ ), não é considerada um indicador relevante para análise.

É importante observar que a característica construtiva desse módulo faz com que a massa de água da bacia fique completamente isolada do contato com o ambiente externo, isso aumenta significativamente o atraso e o amortecimento térmicos em relação ao ambiente externo, o que não ocorre no $\mathrm{ME}$ da configuração 1 , no qual a bacia com água sujeita à evaporação está em contato direto com o ambiente externo, trocando calor por convecção. Dessa forma, parte da redução de temperatura observada no TR vedado e isolado é devida à ausência de trocas por convecção durante o dia (o que traria ganhos de calor para o reservatório d'água), tal qual ocorre em TR aberto e sombreado (configuração 1). Complementarmente, o efeito de aumento de inércia térmica gerada pela massa de água isolada, com alto calor específico, é responsável por uma taxa de aquecimento mais lenta durante o dia. No período noturno, porém, o compartimento d'água cede calor sensível para o ar interno, o que acarreta um aumento da temperatura média de $1,5{ }^{\circ} \mathrm{C}$ em relação ao MC.
Na comparação com a configuração 1 , nota-se que as diferenças encontradas entre o $\mathrm{ME}$ e o $\mathrm{MC}$ (DeltaT [MC-ME] médio e média dos máximos diários), para o período diurno, quando o REI oferece melhor desempenho, é significativamente mais alta na configuraçãol $\left(4,4^{\circ} \mathrm{C}\right.$ e $8,7^{\circ} \mathrm{C}$ versus $1,6^{\circ} \mathrm{C}$ e $3,8^{\circ} \mathrm{C}$, respectivamente). Nota-se, porém, que o desempenho do $\mathrm{MC}$, tomado como referência na comparação em relação ao ambiente externo, difere entre ambas as configurações: DeltaT $\left(\mathrm{T}_{\text {ext }}-\mathrm{MC}\right.$ ) varia de $-0,8{ }^{\circ} \mathrm{C}$ para $-0,4{ }^{\circ} \mathrm{C}$, na média. Entretanto, mesmo normalizando a relação entre o ME e o MC para os dois períodos pelos respectivos valores de DeltaT $\left(\mathrm{T}_{\text {ext }}-\mathrm{MC}\right)$, obtém-se uma relação DeltaT (MC-ME)/ DeltaT $\left(\mathrm{T}_{\text {ext }}-\mathrm{MC}\right)$ 1,5 vez maior para a configuração 1 , o que sugere melhor desempenho quando há utilização do resfriamento evaporativo indireto.

\section{Potencial de Resfriamento Médio (PRM)}

Da mesma forma que fora calculado para a configuração 1 e também para comparação com o experimento similar realizado por González em Maracaibo (GONZÁLEZ-GARCIA, 2010), o PRM obtido para o TR vedado e isolado é apresentado na Figura 16. Uma vez que a segunda configuração não emprega trocas por evaporação, o COP, cujo cálculo baseia-se no processo evaporativo, é desconsiderado para esta análise.

Conforme verificado por González-Garcia, em Maracaibo, em seu experimento 4 (GONZÁLEZGARCIA, 2010), os valores de PRM são baixos e oscilam entre negativo e positivo, sendo sugerido por González que o ME apresenta comportamento térmico similar ao MC. Comparativamente à configuração 1, nota-se também que, conforme discutido por González (GONZÁLEZ-GARCIA, 2010), nessas condições, o ME apresenta comportamento térmico similar ao MC. O PRM máximo obtido para a segunda configuração (cerca de $130 \mathrm{Wh} / \mathrm{m}^{2}$ ) não chega a atingir nem a metade do que se obteve com a primeira configuração (em torno de $300 \mathrm{Wh} / \mathrm{m}^{2}$ ). 


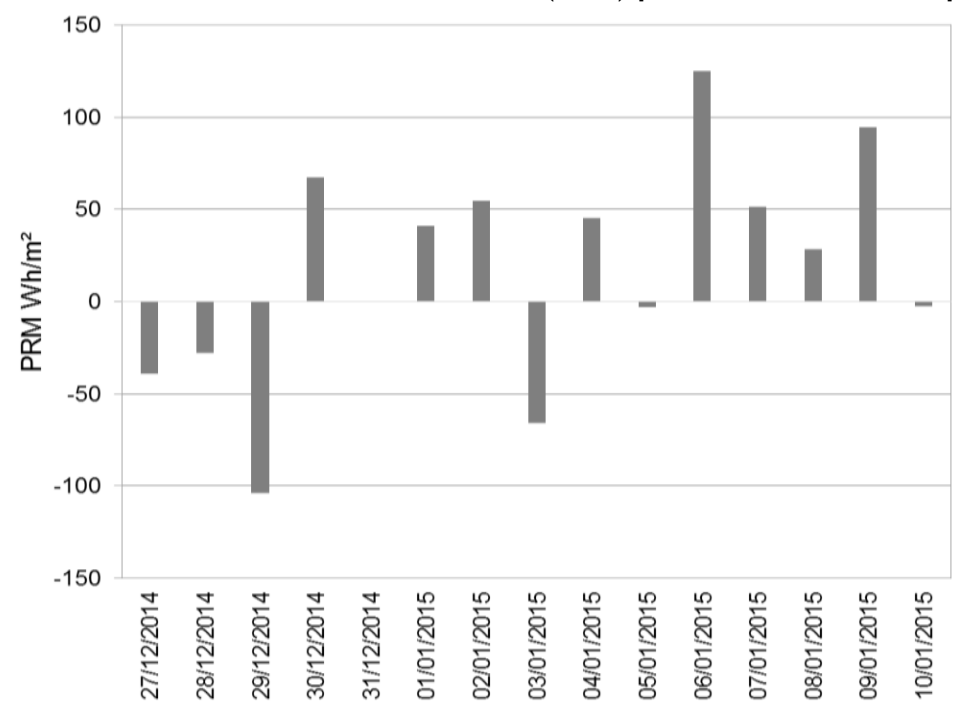

\section{Condições de conforto térmico: potencial de resfriamento}

Conforme calculado para a configuração 1 , a temperatura de conforto foi determinada para o período adotando-se como $\mathrm{T}_{\text {med-ext }}$ a temperatura média registrada no local para o período monitorado (cf. Tabela 3), obtendo-se $25,1{ }^{\circ} \mathrm{C}$. Calculando-se o somatório de diferenças de temperatura acima dessa temperatura-base, obtêmse então um total de $338,6^{\circ} \mathrm{C} . \mathrm{h}$ para o ambiente externo, $428,2{ }^{\circ} \mathrm{C}$.h para $\mathrm{MC}$ e $57,2^{\circ} \mathrm{C}$.h para ME. Comparativamente à configuração 1 , e levando-se em conta o somatório de graus/hora para resfriamento pelo total externo, obtém-se as relações $10,9{ }^{\circ} \mathrm{C} . h / 493,2{ }^{\circ} \mathrm{C} . h$ e $63,3{ }^{\circ} \mathrm{C} . \mathrm{h} / 338,6$ ${ }^{\circ} \mathrm{C} . \mathrm{h}$, o que traduziriam para os percentuais de redução de necessidade de resfriamento de $98 \%$ e de $81 \%$ para as configurações 1 e 2, respectivamente. Confirma-se, assim, o desempenho superior de $\mathrm{ME}$ na primeira configuração, com o sistema REI em funcionamento.

\section{Comparação entre ambas as configurações com base em equações preditivas}

A Figura 17 apresenta a comparação entre as duas configurações de ME, para o primeiro período de medições. A equação gerada para a configuração 2 foi aplicada aos dados do primeiro período.

Nota-se um comportamento térmico dessemelhante entre as duas configurações, cada qual com um fenômeno responsável pela curva de temperatura obtida: para o caso do REI atuante, nota-se uma redução da temperatura interna maior para os dias mais quentes ou com maior oscilação térmica, indicador de céu claro e maior estabilidade atmosférica (HOLMER; THORSSON; LINDÉN, 2013); para a segunda configuração, o efeito de aumento da capacidade térmica da cobertura diminui a amplitude da curva, porém a queda de temperatura durante o período diurno não é tão acentuada como no REI. $\mathrm{O}$ atraso térmico observado nas três situações foi (média para os dias com amplitude térmica igual ou superior a 10 $\mathrm{K})$ : 19 minutos para o MC, 14 minutos para o $\mathrm{ME}$ na primeira configuração e 3 horas para o ME na segunda configuração.

A Tabela 4 mostra algumas relações observadas na comparação entre ambas as configurações. Verifica-se que as temperaturas internas do $\mathrm{ME}$ com uso do REI se situam em média aproximadamente $2{ }^{\circ} \mathrm{C}$ abaixo de $\mathrm{T}_{\text {ext }}$, enquanto o sistema na configuração 2 (massa térmica) mostra uma diferença média de apenas $0,4^{\circ} \mathrm{C}$ abaixo de $\mathrm{T}_{\text {ext }}$. Porém, essa diferença é maior quanto às máximas diárias $\left(5,3{ }^{\circ} \mathrm{C}\right.$ vs. $\left.3,8{ }^{\circ} \mathrm{C}\right)$ e inversa para as mínimas diárias, com a configuração 2 mostrando-se significativamente mais quente durante o período noturno que a configuração 1 , de acordo com os resultados mostrados na Figura 15.

Quanto às diferenças no $\mathrm{MC}$, tanto a média para o período completo quanto a média diurna das diferenças entre $\mathrm{MC}$ e $\mathrm{ME}$ são maiores para a configuração 1. A diferença relativa entre $\mathrm{MC}$ e $\mathrm{ME}$ nas duas configurações mostra um desempenho significativamente maior para a configuração 1 no que se refere ao resfriamento do ambiente interno. A configuração 2, com a massa térmica atuante, traz maiores benefícios apenas para a manutenção do calor no ambiente interno, o que não é o objetivo em situação de verão. 
Figura 17 - Comparação da temperatura interna para as configurações 1 e 2 de ME por método preditivo

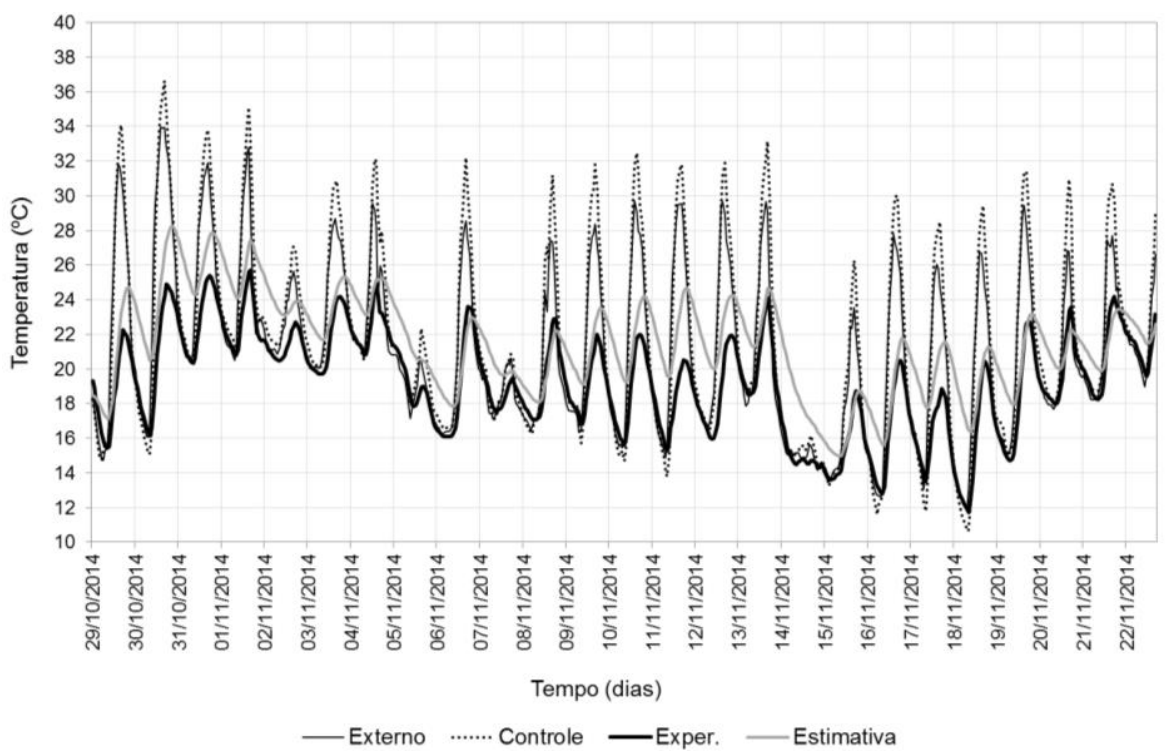

Tabela 4 - Comparativo para o período, diferenças em termos de temperatura do $\operatorname{ar}\left({ }^{\circ} \mathrm{C}\right)$ encontradas nos dois módulos para a configuração 1 (função evaporativa) e para a configuração 2 (função massa térmica)

\begin{tabular}{|c|c|c|c|c|c|c|c|c|}
\hline & \multirow{3}{*}{$\mathbf{T}_{\text {ext }}$} & \multirow{3}{*}{$\begin{array}{c}\mathbf{T}_{\text {int }} \\
(\mathbf{M C})\end{array}$} & & & \multicolumn{2}{|c|}{ Função evaporativa } & \multicolumn{2}{|c|}{ Função massa térmica } \\
\hline & & & $\begin{array}{c}\mathbf{T}_{\text {int }} \\
(\mathbf{M E})\end{array}$ & $\begin{array}{c}\mathbf{T}_{\text {int }} \\
(\mathbf{M E})\end{array}$ & \multirow{2}{*}{$\begin{array}{c}\text { DeltaT } \\
\text { (MC-ME) } \\
24 h\end{array}$} & \multirow{2}{*}{$\begin{array}{c}\text { DeltaT } \\
\text { (MC-ME) } \\
\text { dia }\end{array}$} & \multirow{2}{*}{$\begin{array}{c}\text { DeltaT } \\
\text { (MC-ME) } \\
24 h \\
\end{array}$} & \multirow{2}{*}{$\begin{array}{c}\text { DeltaT } \\
\text { (MC-ME) } \\
\text { Dia }\end{array}$} \\
\hline & & & evap. & massa & & & & \\
\hline Média & 21,1 & 21,7 & 19,1 & 21,5 & 2,6 & 4,3 & 0,3 & 2,5 \\
\hline Máximo & 27,6 & 30,1 & 22,3 & 23,8 & 8,5 & 8,5 & 7,6 & 7,6 \\
\hline Mínimo & 16,5 & 16,3 & 16,6 & 19,4 & $-0,6$ & $-0,2$ & $-3,9$ & $-3,3$ \\
\hline
\end{tabular}

\section{Conclusões}

Este trabalho apresentou resultados iniciais de estudo sobre a utilização de uma tecnologia de baixo consumo energético para condicionamento térmico aplicado a células-teste em período quente em Curitiba.

O estudo mostrou a efetividade do SPR para as condições meteorológicas relativas ao final da primavera e início da estação de verão, em Curitiba. Ficou claro que o resfriamento evaporativo contribuiu para uma maior resistência do ME ao aumento das temperaturas internas do ar e a massa térmica isolada proporciona um significativo aumento do conforto térmico, porém ainda inferior ao que se obtém com o sistema REI em funcionamento. Dessa forma, na comparação com a configuração 2 , baseada apenas no uso do reservatório vedado, com aumento significativo da capacidade térmica do sistema cobertura, porém sem efeito evaporativo, a configuração 1 mostrouse mais eficaz para o resfriamento do ambiente.
Os resultados indicam que os sistemas oferecem alto potencial de resfriamento, tendo este sido superior ao verificado por Gonzalez et al. (2014) e González e Garcia (2010) para as condições climáticas de final de primavera em Florianópolis, localizada na ZB-3 e para Maracaibo, Venezuela.

Etapas futuras da pesquisa envolvem novas configurações e otimização do sistema REI em estudo, e testes em uma edificação experimental, em escala real. Uma limitação do trabalho é que, durante as semanas monitoradas, não se tomaram as temperaturas da água no reservatório e não se acompanhou o consumo diário de água de reposição de forma sistemática.

\section{Referências}

ASSOCIAÇÃO BRASILEIRA DE NORMAS

TÉCNICAS. NBR 15220: desempenho térmico de edificações: parte 3: zoneamento bioclimático brasileiro e diretrizes construtivas para habitações unifamiliares de interesse social. Rio de Janeiro: ABNT, 2003. 
BATISTA, J.; LAMBERTS, R. Estimativas de Redução da Temperatura do Ar: uso do resfriamento evaporativo direto no semi-árido alagoano. In: ENCONTRO NACIONAL DE CONFORTO NO AMBIENTE CONSTRUÍDO, 9., Ouro Preto, 2007. Anais... Ouro Preto: ANTAC, 2007.

CAVALCANTI, J. R. de S. Estudo Experimental Comparativo Entre Resfriamento Evaporativo e Radiativo em Ambientes Cobertos Com Telhas de Fibrocimento em Região de Clima Quente e Úmido. São Paulo, 2001. Dissertação (Mestado em Engenharia Civil) - Escola Politécnica, Universidade de São Paulo, São Paulo: USP, 2001.

CAVALCANTI, J. R. de S.; PRADO, R. T. A. Estudo Experimental Comparativo Entre Resfriamento Evaporativo e Radioativo em Ambientes Cobertos Com Telhas de Fibrocimento em Região de Clima Quente e Úmido. São Paulo: Escola Politécnica da USP, 2001. Boletim Técnico da Escola Politécnica da USP.

DE DEAR, R; BRAGER, G. S. Thermal Comfort in Naturally Ventilated buildIngs: revisions to ASHRAE standard 55. Energy and Buildings, v. 34, n. 6, p. 549-63, 2002.

EMPRESA DE PESQUISA ENERGÉTICA. Balanço Energético Nacional 2013: relatório síntese. Rio de janeiro: Ministério de Minas e Energia, 2013.

EMPRESA DE PESQUISA ENERGÉTICA. Balanço Energético Nacional 2014: relatório síntese. Rio de Janeiro: Ministério de Minas e Energia, 2014.

ERELL, E. Evaporative Cooling. Book Chapter. In: SANTAMOURIS, M. (Ed.). Advances in Passive Cooling. London: James \& James Science Publishers, 2007.

FERNANDES, L. C. Utilização de Equações Preditivas Para Estimativa da Temperatura Interna de Edificações de Interesse Social. Curitiba, 2005. Dissertação (Mestrado em Engenharia Civil) - Programa de Pós-Graduação em Tecnologia, Universidade Tecnológica Federal do Paraná, Curitiba, 2005.
FERNANDES, L. C. et al. Estimativa de Temperaturas Internas Horárias de Pequenas Edificações a Partir de Temperaturas Externas: Proposta de Método Alternativo. In: ENCONTRO NACIONAL SOBRE CONFORTO NO AMBIENTE CONSTRUÍDO E IX ENCONTRO LATINO-AMERICANO SOBRE CONFORTO DO AMBIENTE CONSTRUÍDO, 13., Campinas, 2015. Anais... Campinas: ANTAC, 2015.

GIVONI, B. Comfort Climate Analysis and Building Design Guidelines. Energy and Buildings, v. 18, n. 1, p. 11-23, 1992.

GIVONI, B. Options and Aplications of Passive Cooling. Energy and Buildings, v. 7, n. 4, p. 297300, 1984.

GONZALEZ, E. Étude de Matériaux et de Techniques du Bâtiment Pour la Conception Architecturale Bioclimatique en Climat Chaud et Humide. Paris, 1997. Thèse (Doctorat en Energétique) - l'École des Mines des Paris, Paris, 1997.

GONZALEZ, E.; KRÜGER, E. L. Enfriamento Evaporativo Indirecto: predicción del comportamiento térmico en ciudades brasileñas. In: ENCONTRO NACIONAL, 12.; ENCONTRO LATINO AMERICANO DE CONFORTO NO AMBIENTE CONSTRUÍDO, 8., Brasília, 2013. Anais... Brasília: ANTAC, 2013.

GONZALEZ, E.; KRÜGER, E. L.; GIORDANO, D. E. Estudo da Aplicabilidade de Um Sistema de Resfriamento Evaporativo Indireto Para Otimização do Conforto Térmico em Residências no Território Brasileiro. In: ENCONTRO NACIONAL DE TECNOLOGIA DO AMBIENTE CONSTRUÍDO, 15., Maceió, 20147. Anais... Maceió: ANTAC, 2014.

GONZALEZ, E. M.; CONZALEZ-GARCIA, S. I. Estudio Experimental Sobre el Comportamiento Térmico de Un Nuevo Tipo de Techo-Estanque Para el Enfriamiento Passivo en Clima Húmedo. Ambiente Construído, Porto Alegre, v. 13, n. 4, p. 149-171, out./dez. 2013.

GONZALEZ, E. et al. Estudo Experimental Com Sistemas de Resfriamento Passivo em Florianópolis. In: ENCONTRO NACIONAL DE TECNOLOGIA DO AMBIENTE CONSTRUÍDO, 15., Maceitó, 2014. Anais... Maceió: ANTAC, 2014.

GONZALEZ-GARCIA, S. Estudio Experimental del Comportamiento Térmico de Sistemas Pasivos de Enfriamiento en Clima CálidoHúmedo. Huelva: Universidad Internacional de Andalucía, Sede Internacional de la Rábida, 2010. 
HOLMER, B.; THORSSON, S.; LINDÉN, J. Evening Evapotranspirative Cooling in Relation to Vegetation and Urban Geometry in the ciTy of Ouagadougou, Burkina Faso. International Journal of Climatology, v. 33, n. 15, p. 30893105, 2013.

INSTITUTO NACIONAL DE METEOROLOGIA. Normais Climatológicas do Brasil 1961-1990. Disponível em:

<http://www.inmet.gov.br/portal/index.php?r=clim a/normaisClimatologicas>. Acesso em: 14 abr. 2015.

KRÜGER, E.; GONZÁLEZ CRUZ, E.; GIVONI, B. Effectiveness of Indirect Evaporative Cooling and Thermal Mass in a Hot Arid Climate.

Building and Environment, v. 45, n. 6, p. 14221433, 2010.

KRÜGER, E. L. et al. O Uso de Protótipos Experimentais de Baixo Custo Para Avaliação de Materiais de Vedações Quanto ao Seu Desempenho Térmico. In: CONFERÊNCIA LATINO-AMERICANA DE CONSTRUÇÕES SUSTENTÁVEIS, 1.; ENCONTRO NACIONAL DE TECNOLOGIA DO AMBIENTE CONSTRUÍDO, 10., Sáo Paulo, 2004. Anais... São Paulo: ANTAC, 2004.

KRÜGER, E. L.; RORIZ, M. Previsão Horária de Temperaturas Internas do Ar: aplicação no estudo de células teste. In: ENCONTRO NACIONAL SOBRE CONFORTO NO AMBIENTE CONSTRUÍDO, 8.; ENCONTRO LATINOAMERICANO SOBRE CONFORTO DO AMBIENTE CONSTRUÍDO, 4., Maceió, 2004. Anais... Maceió: ANTAC, 2004.

LABAKI, L. C.; TEIXEIRA, C. F.; TAVARES, S. F. Desempenho Térmico de Técnicas Passivas em Coberturas: resfriamento evaporativo e radiante. In: ENCONTRO NACIONAL SOBRE CONFORTO NO AMBIENTE CONSTRUÍDO,8; ENCONTRO LATINO-AMERICANO SOBRE CONFORTO DO AMBIENTE CONSTRUÍDO, 4., Maceió, 2005. Anais... Maceió: ANTAC, 2005.

LIMA, M. P. Equações Preditivas Para Determinar a Temperatura Interna do Ar: envolventes em painel alveolar com cobertura verde. Sáo Paulo, 2009. Dissertação (Mestrado em Engenharia Ambiental) - Universidade de São Paulo, São Paulo, 2009.
MONTEIRO, J. R. V. Influência da Envoltória Vertical Opaca de Edificações nas Temperaturas Internas do Ar. Joáo Pessoa, 2013. Dissertação (Mestrado em Engenharia Urbana e Ambiental) - Programa de PósGraduação em Engenharia Urbana e Ambiental, Universidade Federal da Paraíba, João Pessoa, 2013.

NASCIMENTO, G. R. Refrigeração Evaporativa de Telhados Por Meio de Gotejamento de Água: experimento em bancada de testes. Sáo Carlos, 2005. Dissertação (Mestrado em Engenharia Civil) - Programa de Pós-Graduação em Construção Civil, Universidade Federal de São Carlos, São Carlos, 2005.

PAPST, A. L. Método Estimativo da Temperatura Interna de Edificações Residenciais em Uso. Florianópolis, 2004. Tese (Dissertação em Engenharia Civil) - Programa de Pós- Graduação em Engenharia Civil, Universidade Federal de Santa Catarina, Florianópolis, 2004.

RORIZ, V.; RORIZ, M. Resfriamento Evaporativo Por Aspersão de Água Sobre Telhas de Fibrocimento em Clima Semi-Úmido. In: ENCONTRO NACIONAL DE TECNOLOGIA DO AMBIENTE CONSTRUÍDO, 12., Fortaleza, 2008. Anais... Fortaleza: ANTAC, 2008.

SÁNCHES, L. H. G. Evaluación de un Techo Estanque Como Sistema de Enfriamiento Pasivo en un Clima Cálido Sub-húmedo. Colima, 1993. Dissertação - Universidad de Colima, Facultad de Arquitectura - Maestría en DiseBo Bioclimático, 1993.

SHARIFI, A.; YAMAGATA, Y. Roof Ponds as Passive Heating and Cooling Systems: a systematic review. Applied Energy, v. 160, p. 336-357, 2015.

SILVA, A. C. S. B. da. Simulação de Resfriamento Evaporativo Por Microaspersão d'Água. Florianópolis, 2004. Tese (Dissertação em Engenharia Civil) - Programa de PósGraduação em Engenharia Civil, Universidade Federal de Santa Catarina, Florianópolis, 2004

VECCHIA, F.; MASIERO, É. Resfriamento Evaporativo e Condicionamento de $\mathrm{Ar}$ Convencional: estudo experimental comparativo para a obtenção do conforto humano. In: ENCONTRO NACIONAL DE TECNOLOGIA DO AMBIENTE CONSTRUIIDO, 21 Florianópolis, 2006. Anais... Florianópolis: ANTAC, 2006. 


\section{Eduardo Leite Krüger}

Departamento de Construção Civil, Programa de Pós-Graduação em Tecnologia; Programa de Pós-Graduação em Engenharia Civil । Universidade Tecnológica Federal do Paraná | Av. Sete de Setembro, 3165 | Curitiba - PR - Brasil | CEP 80230-901 | Tel.: (41) 3310-4725 | E-mail: ekruger@utfpr.edu.br

\section{Sérgio Costa Lange}

Programa de Pós Graduação em Tecnologia | Universidade Tecnológica Federal do Paraná | E-mail: sc_lange@hotmail.com

\section{Leandro Carlos Fernandes}

Departamento de Expressão Gráfica, Centro Politécnico | Universidade Federal do Paraná | Edifício da Administração, $4^{\circ}$ Andar, Jardim das Américas | Curitiba - PR - Brasil | CEP 81531-970 | Tel.: (41) 3361-3039 | E-mail: fernandes.ufpr@gmail.com

\section{Francine Aidie Rossi}

Departamento de Expressão Gráfica, Centro Politécnico | Universidade Federal do Paraná | E-mail: francinea.rossi@hotmail.com

\section{Revista Ambiente Construído}

Associação Nacional de Tecnologia do Ambiente Construído

Av. Osvaldo Aranha, $99-3^{\circ}$ andar, Centro

Porto Alegre - RS - Brasil

CEP 90035-190

Telefone: +55 (51) 3308-4084

Fax: +55 (51) 3308-4054

www.seer.ufrgs.br/ambienteconstruido

E-mail: ambienteconstruido@ufrgs.br 